\title{
Yogurt starter cultures of Streptococcus thermophilus and Lactobacillus bulgaricus ameliorate symptoms and modulate the immune response in a mouse model of dextran sulfate sodium-induced colitis
}

\section{E. Wasilewska, ${ }^{*}$ D. Zlotkowska, and B. Wroblewska}

Department of Immunology and Food Microbiology, Institute of Animal Reproduction and Food Research, Polish Academy of Sciences, 10-748 Olsztyn, Poland

\section{ABSTRACT}

We investigated the yogurt starter cultures of Lactobacillus bulgaricus 151 and Streptococcus thermophilus MK-10 for their effect on the severity of experimental colitis, lymphocyte profile, and regulatory T-cell response. Colitis was induced in BALB/c mice via the administration of $3.5 \%$ dextran sulfate sodium salt (DSS) in drinking water for $6 \mathrm{~d}$. Next, the mice were gavaged intragastrically with an active yogurt cultures (YC) mixture $\left(\sim 5 \times 10^{9} \mathrm{cfu} /\right.$ mouse per day $)$ or saline (vehicle) for $8 \mathrm{~d}$. Mice receiving DSS or saline alone served as positive and negative controls, respectively. The length of the colon, disease activity index, histological scores, myeloperoxidase activity, epitheliumassociated microbes, short-chain fatty acid profile, total IgA antibody-forming cells, $\mathrm{CD} 3^{+} \mathrm{CD} 8^{+}, \mathrm{CD} 3^{+} \mathrm{CD} 4^{+}$, $\mathrm{CD} 3{ }^{+} \mathrm{CD} 4^{+} \mathrm{CD} 25^{+}, \quad \mathrm{CD} 3{ }^{+} \mathrm{CD} 4^{+} \mathrm{CD} 25^{+} \mathrm{Foxp}^{+} \quad$ T-cell subsets, and cytokine profiles (IL-2, IL-4, IL-6, IL-10, IL-17A, IFN- $\gamma$, and tumor necrosis factor) were examined after termination of the mice. Feeding mice with YC mixture reduced disease symptoms and modified intestinal microbiota and host inflammatory responsiveness to DSS. We observed limited weight loss and a decreased disease activity index score, lowered myeloperoxidase activity, and somewhat reduced damage of the intestine. The YC mixture upregulated the colon length, increased the amount and diversity of mucosaassociated microbes (enterobacteria, enterococci, and yeast), and decreased the concentration of putrefactive short-chain fatty acids in the cecal contents. It downregulated the input of cytotoxic $\mathrm{CD} 3^{+} \mathrm{CD} 8^{+} \mathrm{T}$ cells and $\mathrm{CD} 3{ }^{+} \mathrm{CD} 4{ }^{+} \mathrm{CD} 25^{+} \mathrm{FoxP} 3^{+}$regulatory $\mathrm{T}$ cells in Peyer's patches and enhanced $\mathrm{CD} 3^{+} \mathrm{CD} 4^{+} \mathrm{CD} 25^{+} \mathrm{T}$ cells in spleens and $\mathrm{CD} 3^{+} \mathrm{CD} 4^{+} \mathrm{CD} 25^{+} \mathrm{FoxP}^{+}$cells in peripheral blood mononuclear cells. Simultaneously,

Received January 30, 2018.

Accepted August 29, 2018.

*Corresponding author: e.wasilewska@pan.olsztyn.pl
IgA antibody-forming cells were downregulated in mesenteric lymph nodes (MLN) and enhanced in spleens (SPL). The cultures mostly enhanced the production of cytokines tested in MLN and SPL, except for IL-6, which was downregulated in MLN. Interleukin-2 and IL-4 were the most upregulated in MLN, whereas IL-10, IL-4, IL-2, IFN- $\gamma$, and tumor necrosis factor were most upregulated in SPL. In serum, the YC mixture downregulated IFN- $\gamma$ and clearly increased IL-2. Based on these results, we recognize the high anti-inflammatory and immunomodulatory potential of the L. bulgaricus 151 and S. thermophilus MK-10 set. The strains possess the ability to modulate the intestinal mucosal and systemic immune system toward both IgA production and induction of regulatory $\mathrm{T}$ cells, shifting Th1/Th2 balance.

Key words: yogurt culture, Streptococcus thermophilus, Lactobacillus bulgaricus, dextran sulfate sodiuminduced colitis, regulatory $\mathrm{T}$ cell

\section{INTRODUCTION}

Yogurt has been recognized as a healthy food with therapeutic properties. Except for traditional products fermented with Streptococcus thermophilus and Lactobacillus bulgaricus, many bio-yogurts have been reformulated to include other Lactobacillus and Bifidobacterium species, the presence of which may produce the claimed beneficial health effects. Thus far, the nutritional value of yogurt has been well recognized (Lourens-Hattingh and Viljoen, 2001). Numerous studies have also suggested the beneficial therapeutic effects of bacteria present in yogurt on health; however, these health benefits are often attributed to the ingestion of probiotic-containing yogurts (Granato et al., 2010; Wroblewska et al., 2011). Probiotics influence the host health and its immune system and possess the potential to control inflammation (Ghouri et al., 2014; Berg et al., 2015; Wasilewska and Wroblewska, 2018). Knowledge on the activity of yogurt cultures in the gut 
remains limited, presumably because $S$. thermophilus and $L$. bulgaricus do not belong to the indigenous gut microbiota and poorly survive passage through the gut (Elli et al., 2006).

The gut harbors well-balanced microbial communities in the mucosa, lumen, and feces. These microbes participate in metabolic, nutritional, physiological, and immunological processes in the body; hence, crosstalk exists to control their growth and preserve intestinal homeostasis, resulting in differential host responses to commensal and pathogenic microbes (Macpherson and Harris, 2004). Failure of these regulatory mechanisms or imbalance of the gut microbiota may result in an abnormal immune response and pathology such as inflammatory bowel disease (IBD).

Probiotic therapies have appeared to be effective in IBD management, especially in ulcerative colitis (Derwa et al., 2017; Wasilewska and Wroblewska, 2018). The efficacy of yogurt to improve IBD treatment has been poorly investigated, even with those containing probiotic cultures (Lorea Baroja et al., 2007; de Assis et al., 2016; Sheikhi et al., 2016). So far, despite the recognized nutritional and health benefits, traditional yogurt cultures in IBD were examined sporadically, and studies, although optimistic, have been conducted on single strains. Ito et al. (2008) found that S. thermophilus YIT 2001 with antioxidative activity revealed an improving effect on dextran sulfate sodium (DSS)induced colitis. According to Takamura et al. (2011), L. bulgaricus OLL1181 could activate the aryl hydrocarbon receptor pathway, which plays an important role in the regulation of the inflammatory response. Ogita et al. (2011) described the anti-inflammatory effect of S. thermophilus ST28, which could result from its ability to suppress the excessive Th17 response in inflamed intestines.

Yogurt starter cultures are selected and combined into symbiotic sets; therefore, to assess their therapeutic activity, the combined strains (sets) should be tested because their physiological activity may be the result of the combined activity of both strains. Streptococcus thermophilus MK-10 and L. bulgaricus 151 are a compatible strain pair with mutual symbiosis and competition, resulting in balanced growth and synergism reinforcing their technological features and biochemical activity (Bielecka et al., 1994a,b; Bielecka and Majkowska, 2000; Bielecka et al., 2000).

Evidence exists that all-trans retinoic acid is required for establishing immune tolerance to dietary antigens in the upper gut, whereas microbial metabolites such as short-chain fatty acids (SCFA) can regulate microbiota-specific regulatory $\mathrm{T}$ cells (Tregs) in the colon (Smith et al., 2013). The Tregs, such as $\mathrm{CD} 3{ }^{+} \mathrm{CD} 4^{+} \mathrm{CD} 25^{+} \mathrm{Foxp}^{+}$, and regulatory cytokines play key roles in various immune response and protection against autoimmune diseases (Curotto de Lafaille and Lafaille, 2009; Buckner, 2010). The aim of our study was to identify whether yogurt starter cultures S. thermophilus MK-10 and L. bulgaricus 151 possess the capacity to moderate the symptoms of experimental colitis and alter the cytokine profile and induce the Treg response in a mouse model of DSS-induced colitis.

\section{MATERIALS AND METHODS}

\section{Bacterial Strains}

The S. thermophilus MK-10 and L. bulgaricus 151 strains used in the study originated from our own collection and were previously identified as starter cultures displaying synergistic effects during the manufacture of yogurt (Bielecka and Majkowska, 2000). For the experiment, S. thermophilus was cultured in M17 broth (Merck KGaA, Darmstadt, Germany) and L. bulgaricus was cultured in de Man, Rogosa, Sharpe broth (Merck $\mathrm{KGaA}$ ) at $37^{\circ} \mathrm{C}$ until the stationary phase was achieved (the growth to about $5 \times 10^{8} \mathrm{cfu} / \mathrm{mL}$ and $1 \times 10^{9} \mathrm{cfu} /$ $\mathrm{mL}$, respectively, as was determined on M17 and de Man, Rogosa, Sharpe agar media). Next, the cultures were combined in the cell proportion they usually reach during yogurt manufacturing (i.e., 1:1.2, lactobacilli to streptococci, respectively), centrifuged $(5,000 \times g, 15$ min, $4^{\circ} \mathrm{C}$ ), and the unwashed pellet was resuspended in sterile saline and further incubated at $37^{\circ} \mathrm{C}$ for $4 \mathrm{~h}$. This culture [yogurt culture (YC) mixture] was used for experiments, as it contained about $2.5 \times 10^{10} \mathrm{cfu} /$ $\mathrm{mL}$ of bacterial cells and was made daily throughout the entire experimental period.

\section{Mice and Experimental Design}

Specific-pathogen-free BALB/c mice (female, $8 \mathrm{wk}$ old) weighing $20 \pm 2 \mathrm{~g}$ were used in the study. All mice were purchased from Animal House of the Mossakowski Medical Research Centre of the Polish Academy of Science in Warsaw (Poland). For the experiment, the animals were maintained in individual ventilated cages under controlled environmental conditions [room temperature $\left(22 \pm 2^{\circ} \mathrm{C}\right)$ with $50 \pm 10 \%$ humidity and controlled 12-h light/dark cycle] and were fed totalpathogen-free 1324 maintenance diet (Altromin, Lage, Germany) and water ad libitum.

For the experiments, the mice were randomly assigned to 3 groups ( $\mathrm{n}=12$ /group) and were acclimated for $7 \mathrm{~d}$. A natural enteric flora transfer step was then performed to reduce the variability in disease onset and severity. Dirty beddings were mixed and homogenized, and equal parts were spread over new litters. 


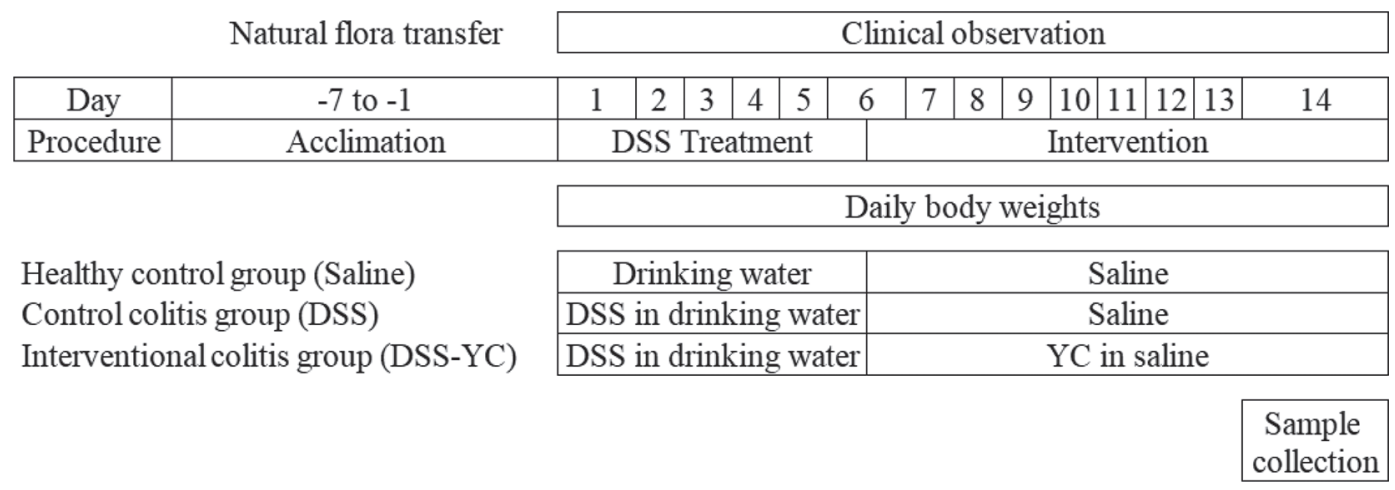

Figure 1. Schema of the experimental design. DSS = dextran sulfate sodium salt; YC = yogurt cultures.

Colitis was induced in 2 groups by feeding the mice $3.5 \%$ dextran sulfate sodium salt (DSS; molecular weight $=36,000-40,000$ Da; Sigma-Aldrich, Steinheim, Germany) in drinking water ad libitum for $6 \mathrm{~d}$. At the end of d 6, all DSS-administered mice were returned to drinking plain water. Following the discontinuation of DSS, on d 6, supplementary feeding was started (Figure $1)$. The treatment colitis group (DSS-YC group) was administered $200 \mu \mathrm{L} / \mathrm{d}$ per mouse of the YC mixture $\left(\sim 5 \times 10^{9}\right.$ cfu per mouse) intragastrically for the next 8 d. The control colitis group (DSS group) served as the primary comparison with the YC intervention group and received saline intragastrically as a vehicle. The saline group comprised the healthy controls and received normal drinking water ad libitum (without DSS) throughout the entire study and $200 \mu \mathrm{L} / \mathrm{d}$ per mouse of saline intragastrically during the intervention.

The mice were monitored daily for BW, stool consistency, and fecal blood, and the disease activity index (DAI) was calculated as described below. The mice were euthanized on d 14, after $8 \mathrm{~d}$ of interventional feeding. Immediately after euthanasia by carbon dioxide inhalation, the abdominal skin of the mouse was sprayed with $70 \%$ ethanol and blood was taken by cardiac puncture. Next, the spleens (SPL), mesenteric lymph nodes (MLN), colons, and Peyer's patches (PP) were carefully taken to avoid contamination for lymphocyte isolation or for histological, biochemical, or microbiological examinations. The length of the colon was measured as described below. All animal care and procedures were in accordance with institutional policies for animal health and well-being and were approved by the Institutional Animal Ethics Committee (Approval no 79/2011).

\section{DAl}

A DAI score was computed as the combined scores of the established scoring system (Kim et al., 2012) com- prising percentage of $\mathrm{BW}$ loss $(1-5 \%$ weight loss $=0$ to $>20 \%$ weight loss $=4$ ), stool consistency (normal pellets $=0$ to diarrhea $=4$ ), and rectal bleeding (no rectal bleeding $=0$ to visible gross bleeding blood around anus $=4)$. The percentage of BW loss was calculated to the initial value at the beginning of the experiment. Occult blood in feces was measured using the Hemoccult test (Beckman Coulter Inc., Brea, CA).

\section{Colon Length and Histological Evaluation}

The length of the colon from the ileocecal junction to the anus was measured before it was quickly flushed using cold PBS (10 mM, pH 7.4) to remove feces and blood. The distal segment of the colon $(\sim 1.0 \mathrm{~cm})$ of each mouse was fixed in $10 \%$ buffered formalin solution and embedded in paraffin blocks. Cross sections $(4 \mu \mathrm{m})$ were stained with hematoxylin and eosin and examined by an experienced histopathologist blinded to the intervention. Inflammation was assessed based on an established scoring system (Kim et al., 2012) comprising crypt architecture (normal $=0$ to severe crypt distortion with loss of entire crypts $=3$ ), degree of inflammatory cell infiltration (normal $=0$ to dense inflammatory infiltrate $=3$ ), muscle thickening (base of crypt sits on the muscularis mucosae $=0$ to marked muscle thickening present $=3$ ), goblet cell depletion (absent $=0$ to present $=1$ ), and crypt abscess (absent $=0$ to present $=1$ ). The histological damage score was computed as the sum of each individual score.

\section{Myeloperoxidase Activity Assay}

Colonic myeloperoxidase (MPO) activity was measured according to the method of Kim et al. (2012) with minor modifications. Briefly, the frozen middle segment of the colon $(25-50 \mathrm{mg})$ was homogenized in ice-cold lysis buffer $(50 \mathrm{~m} M$ potassium phosphate buffer containing $0.5 \%$ of hexadecyltrimethylammonium bromide, 
$\mathrm{pH}$ 6). The obtained homogenate was centrifuged at $13,000 \times g$ for $10 \mathrm{~min}$ at $4^{\circ} \mathrm{C}$ to remove insoluble parts. Next, aliquots of the supernatant were dispensed in 96well plates and mixed with the MPO assay buffer at a ratio 1:29. The MPO assay buffer contained $50 \mathrm{mM}$ phosphate buffer ( $\mathrm{pH}$ 6) diluted with distilled water at a ratio $1: 9, o$-dianisidine dihydrochloride $(0.167 \mathrm{mg} /$ $\mathrm{mL}$ ), and $0.0006 \%$ of hydrogen peroxide. Three subsequent readings of absorbance at $450 \mathrm{~nm}$ were taken at 30-s intervals using a spectrophotometer. The MPO activity was measured in units of MPO per milligram tissue ( $\mathrm{U} / \mathrm{mg}$ tissue), where $1 \mathrm{U}$ of MPO was defined as the amount needed to degrade $1 \mu \mathrm{mol}$ of $\mathrm{H}_{2} \mathrm{O}_{2} / \mathrm{min}$ at room temperature.

\section{Epithelium-Associated Microbiota}

Frozen proximal segments of the colons $(\sim 2.5 \mathrm{~cm})$ were transferred to an anaerobic workstation filled with a $90 \% \mathrm{~N}_{2}, 5 \% \mathrm{CO}_{2}$, and $5 \% \mathrm{H}_{2}$ gas mixture (Bactron600 Anaerobic Chamber, Sheldon Manufacturing Inc., Cornelius, OR). Segments were cut longitudinally, washed 3 times serially in cold saline, weighed, homogenized, and serially diluted 10-fold with an anaerobic diluent. Dilutions were inoculated $(100 \mu \mathrm{L})$ into culture medium. Total anaerobes were enumerated on BBL Schaedler's agar enriched with vitamin $\mathrm{K}_{1}$ and $5 \%$ sheep blood (BD, Sparks, MD), Bifidobacterium were counted on modified Garche's agar (Wasilewska et al., 2008), and sulfite-reducing bacteria were counted on Difco Differential Reinforced Clostridial Agar (BD). The plates were left in the anaerobic chamber incubator at $37^{\circ} \mathrm{C}$ for $72 \mathrm{~h}$. For the evaluation of aerobic and facultative anaerobic bacteria, aliquots were plated on appropriate agar medium under aerobic conditions and were incubated at $37^{\circ} \mathrm{C}$ for $48 \mathrm{~h}$. Enterobacteriaceae were enumerated on Difco MacConkey's agar with crystal violet (BD). Lactobacilli were enumerated on MRS agar (Merck KGaA) plates overlaid with a second layer of medium. Enterococci were enumerated on Kanamycin Esculin Azide Agar (Merck KGaA), and yeasts were enumerated on Difco Sabouraud's Dextrose Agar with chloramphenicol (BD). The identity of representative colonies recovered from the selective medium was confirmed by conventional microbiological tests, including colony appearance (examined under a stereoscopic microscope SZX9; Olympus, Tokyo, Japan), cellular morphology (examined by phase contrast microscopy; Microphot FXA, Nikon, Tokyo, Japan), Gram staining, and biochemical patterns using API systems (BioMerieux, Marcy-l'Etoile, France). Genus affiliation of the grown bifidobacteria was also checked based on the presence of bifidobacteria-specific fructose-6-phospho- ketolase (F6PPK-EC 4.1.2.22; Scardovi, 1986). Bacterial counts were expressed as the log of the number of colony-forming unit per gram of tissue.

\section{SCFA}

Samples of cecal contents preserved in $0.1 \%$ trifluoroacetic acid $(1: 1, \mathrm{vol} / \mathrm{vol})$ and immediately frozen in liquid nitrogen and stored at $-80^{\circ} \mathrm{C}$ were used for the analysis of SCFA. The analysis was performed using an Agilent 7890A gas chromatography system coupled with a flame ionization detector and a 7683B autoinjector (Agilent Technologies, Santa Clara, CA). The SCFA were separated using an SGE BP21 capillary column $(30 \mathrm{~m} \times 0.53 \mathrm{~mm}$; film thickness $=0.5$; SGE Analytical Science, Melbourne, Australia). Helium was supplied as the carrier gas at flow rate of $5 \mathrm{~mL} / \mathrm{min}$. The initial oven temperature was $85^{\circ} \mathrm{C}$, raised to $180^{\circ} \mathrm{C}$ at $6^{\circ} \mathrm{C} / \mathrm{min}$, and held for $5 \mathrm{~min}$. The temperature of the flame ionization detector and injection port were 290 and $250^{\circ} \mathrm{C}$, respectively. Samples $(0.5 \mu \mathrm{L}$ of clear supernatant) were injected in a split mode with a ratio of 10:1. The content of the individual compounds was measured using external standards of acetic, propionic, butyric, valeric, isovaleric, and lactic acid (Sigma-Aldrich, Saint Louis, MO).

\section{IgA Antibody-Forming Cells ELISpot Assay}

The lymphocytes were isolated from MLN and SPL and were added to anti-mouse IgA-coated 96-well plates (MultiScreen Filter Plates; Merck-Millipore, Cork, Ireland) at $10^{5}$ cells per well. After $24 \mathrm{~h}$ of incubation in a $5 \% \mathrm{CO}_{2}$ atmosphere at $37^{\circ} \mathrm{C}$, the plates were washed 4 times with PBST (PBS with $0.1 \%$ Tween 20). Next, horseradish peroxidase-conjugated secondary antibodies (Sigma Aldrich) were added at a dilution of 1:1,000 to the plate and were left for the next $24 \mathrm{~h}$ at $4^{\circ} \mathrm{C}$ in a humidity chamber. After the final washing step, the color reaction was developed by using 3-amino-9-ethylcarbazole (Moss Inc., Pasadena, MD). The plates were incubated for 15 to $60 \mathrm{~min}$ at room temperature and thereafter washed with top water. The spots were read the next day using a stereo zoom microscope (SZX9, Olympus). The results were presented as the number of IgA antibody-forming cells (AFC) for $10^{5}$ cells.

\section{Lymphocyte Isolation and Flow Cytometry Analysis}

Lymphocytes were isolated from SPL, MLN, PP, and blood. Peripheral blood mononuclear cells were isolated using a density gradient technique. Anticoagu- 
lated blood was subjected to Histopaque-1077 density gradient centrifugation (Sigma-Aldrich). The cells were collected from the interface, washed, and phenotyped. Splenic, MLN, and PP lymphocytes were isolated using the conventional method (Holmes et al., 2001; Zlotkowska et al., 2012). Briefly, each tissue was homogenized by the Dounce homogenizer, passed through a Nitex filter $(80-\mu \mathrm{m}$ nylon mesh; Small Parts Inc., Miami, FL) to remove debris, and washed in IM medium [RPMI 1640 medium (Sigma-Aldrich) supplemented with $1 \mathrm{~m} M$ sodium pyruvate, $1 \mathrm{~m} M$ NEAA, and $10 \mathrm{U} /$ $\mathrm{mL}$ penicillin-streptomycin]. Splenocytes were additionally lysed with red cell lysing buffer (Sigma-Aldrich) followed by the washing step. The washed cell pellets were suspended in $1 \mathrm{~mL}$ of CM medium (RPMI 1640 medium supplemented with $1 \mathrm{~m} M$ sodium pyruvate, 1 $\mathrm{m} M \mathrm{NEAA}, 10 \mathrm{U} / \mathrm{mL}$ penicillin-streptomycin, and $10 \%$ fetal bovine serum). The viability of cells was determined by Trypan blue staining.

For flow cytometry phenotyping, the lymphocytes were washed twice with FACS buffer (10 mM PBS supplemented with $2 \%$ fetal bovine serum) and then were stained with rat anti-mouse CD3-PerCP-Cy5.5 (clone 17A2), CD4-FITC (clone H129.19), CD8-APC (clone 53-6.7), and CD25-PE-Cy7 (clone PC61) monoclonal antibodies (BD Biosciences, San Diego, CA). After 15 min of incubation on ice, the cells were washed with FACS buffer, fixed with BD Cytofix Fixation Buffer (Cat. No. 554655) on ice for $30 \mathrm{~min}$, and washed and permeabilized with BD Cytofix/Cytoperm Fixation and Permeabilization Solution (Cat. No. 554722) at room temperature (RT) for $30 \mathrm{~min}$. After the washing step in FACS buffer, the cells were stained with rat anti-mouse Foxp3-PE monoclonal antibodies (clone MF23; BD Biosciences) at RT for $30 \mathrm{~min}$. After final washing, all samples were subjected to flow cytometry analysis using a BD LSRFortessa system (BD Biosciences). All incubations were performed in the dark. At least 50,000 events were collected for each sample. The data were analyzed using Flow Jo software (Tree Star Inc., Ashland, OR).

\section{Cytokine Measurements}

Freshly isolated MLN or splenic lymphocytes $(5 \times$ $10^{6}$ cells $/ \mathrm{mL}$ ) were cultured in CM medium in 48-well cell culture plates for $4 \mathrm{~d}$ in a total volume of $300 \mu \mathrm{L}$ per well. Thereafter, the supernatants were harvested by centrifugation $\left(16,900 \times g, 10 \mathrm{~min}, 4^{\circ} \mathrm{C}\right)$ and stored until analysis at $-80^{\circ} \mathrm{C}$. The harvested blood, after coagulation at room temperature (30 $\mathrm{min})$, was centrifuged at $13,500 \times g$ for $10 \mathrm{~min}$ at $4^{\circ} \mathrm{C}$, and the serum was stored at $-80^{\circ} \mathrm{C}$ until analysis.
Concentration of cytokines IL-10, IL-17A, IFN- $\gamma$, tumor necrosis factor (TNF), IL-6, IL-4, and IL-2 in the culture supernatants and in blood serum samples were measured using the mouse Th1/Th2/Th17 CBA kit (cat. no. 560485, BD Biosciences). Protocols were performed according to the manufacturer's instructions. Briefly, $50 \mu \mathrm{L}$ of sample was mixed with $50 \mu \mathrm{L}$ of the mixed capture beads and $50 \mu \mathrm{L}$ of the mouse detection reagent. After incubation at RT for $2 \mathrm{~h}$ in the dark, the samples were washed and suspended in $300 \mu \mathrm{L}$ of wash buffer and acquired on BD LSRFortessa system. At least 10,000 events were collected for each sample. The data were analyzed using the CBA analysis software (FCAP Array; BD Biosciences). The concentration of each cytokine was calculated using the corresponding standard curve.

\section{Statistical Analysis}

The values for all measurements were expressed as means $\pm \mathrm{SD}$. The $t$-test was used to evaluate differences between groups for parametric data and the MannWhitney test for nonparametric data. The results were considered to be statistically significant if $P<0.05$.

\section{RESULTS}

\section{S. Thermophilus MK10 and L. Bulgaricus 151 Ameliorate DSS-Induced Colitis}

The DSS-induced colitis murine model is commonly used to examine the pathogenesis of IBD and test the efficiency of experimental therapies, including probiotics and clinical nutrition. In our study, feeding mice with DSS via drinking water led to colitis, macroscopically characterized by BW loss, changed stool consistency, and rectal bleeding. Figure 2 illustrates the BW changes in the tested groups during the study. Mice in the control saline group showed relatively constant BW. Only $2 \%$ body mass gain was noted throughout the experiment, whereas changes in the body mass of the remaining groups were significant. The DSS itself caused a sharp decrease in BW from d 5 to 9 , when the highest weight loss $(18 \%)$ was noted $(P<0.05$ vs. saline group). Thereafter, gradual body mass gain (from 82 to $93 \%$ of the initial weight) occurred; however, the differences remained significant $(P<0.05$ vs. saline group). The BW of DSS-administered mice fed the YC set was sharply reduced from d 5 to $7(P<0.05$ vs. saline group); thereafter, BW increased from $87 \%$ of the initial mass at $\mathrm{d} 7$ to $99 \%$ at the end of the experiment. From $\mathrm{d} 8$ to the end of the experiment, the DSS-YC group differed in body mass from both the saline- and 


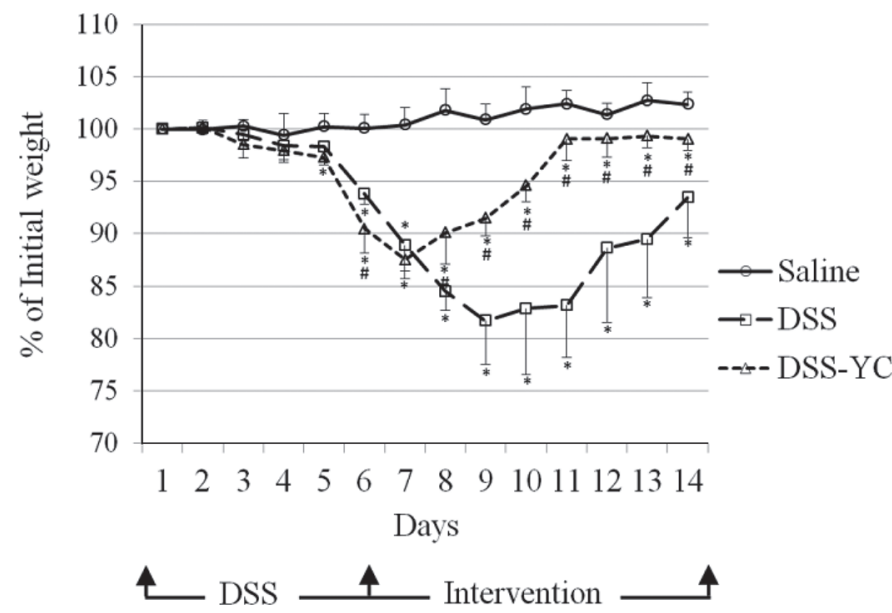

Figure 2. Body weight changes among different groups of mice. Saline $=$ healthy control group [without dextran sulfate sodium salt (DSS)], received saline during intervention; DSS $=$ control colitis group, received saline during intervention; DSS-YC = interventional colitis group, received yogurt culture (YC) mixture during intervention. The data are expressed as the means \pm SD. Statistical analysis was performed by Mann-Whitney test. ${ }^{*} P<0.05$ in comparison with saline group; ${ }^{\#} P<0.05$ in comparison with DSS group.

DSS-treated mice $(P<0.05)$. The DAI score at $\mathrm{d} 9$, when the highest BW loss was noted, was the highest in the DSS mice and differed from both the saline and DSS-YC groups $(P<0.01$ and $P<0.05$, respectively; Figure $3 \mathrm{~A}$ ). Administration of the $\mathrm{YC}$ mixture relieved the macroscopic severity of colitis and decreased the DAI score in acute phase at d $9(P<0.05$ vs. DSS group). On d 14, we observed clinical improvement in both the DSS and DSS-YC groups; however, the recovery was better, although not statistically different, in the YC-treated animals (Figure 3B; $P=0.061$ vs. DSS group). We found no difference in the DAI scores between the saline and DSS-YC groups $(P=0.174)$, unlike the saline and DSS groups $(P<0.01)$.

After termination of the experiment, we scored the severity of colitis based on the shortening of the colon length and by histological and biochemical evaluation. Shortening of the colon is a typical marker of inflammation in DSS-induced colitis. The mice in the control colitis group have reduced colon lengths compared with the healthy group $(P<0.01$; Figure $4 \mathrm{~A})$, whereas the colon lengths in saline and DSS-YC groups were similar and amounted $86.60 \pm 5.50$ and $85.60 \pm 7.02$ $\mathrm{mm}$, respectively. Microscopic examination of histological sections of the colonic tissue showed integral epithelium and no inflammatory cell infiltration in the saline group, as well as increased histology score resulting from increased infiltration and changes in the mucosal architecture with signs of crypt damage, muscle thickening, and goblet cell depletion in the tissue of the control colitis mice (Figure 4B; $P<0.01$ vs. saline group). Feeding mice with $\mathrm{YC}$ ameliorated the histological signs of DSS-induced colitis (Figure 4C). The histology score decreased from $5.33 \pm 1.63$ in DSS group to $2.83 \pm 1.47$ in DSS-YC-administered mice $(P$ $<0.05)$. However, we still noted a difference in this assessment between saline and DSS-YC group $(P<0.05)$. Myeloperoxidase is a lysosomal protein that is most abundantly expressed in neutrophil granulocytes, where it is stored in azurophilic granules and released into the extracellular space during degranulation. Colonic MPO activity is a benchmark of neutrophil infiltration into inflamed tissue; thus, it is considered the hallmark of acute inflammation. Compared with the healthy group, the mice in the DSS colitis group showed increased MPO activity $(P<0.01)$, which was attenuated in the DSS-YC group $(P<0.05$ vs. DSS group; Figure 4D).
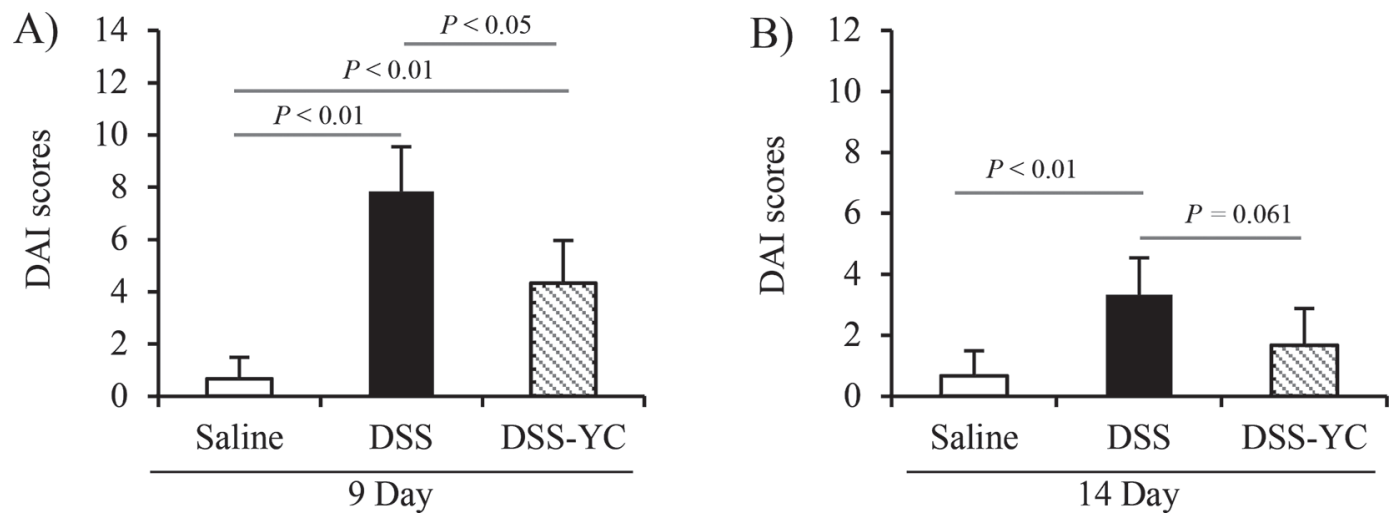

Figure 3. Disease activity index (DAI) score in the saline, dextran sulfate sodium salt (DSS), and DSS-yogurt culture (YC) groups at d 9 (A) and 14 (B). Saline = healthy control group (without DSS), received saline during intervention; DSS = control colitis group, received saline during intervention; DSS-YC = interventional colitis group, received yogurt culture mixture during intervention. The data are expressed as the means \pm SD. Statistical analysis was performed by Mann-Whitney test. 

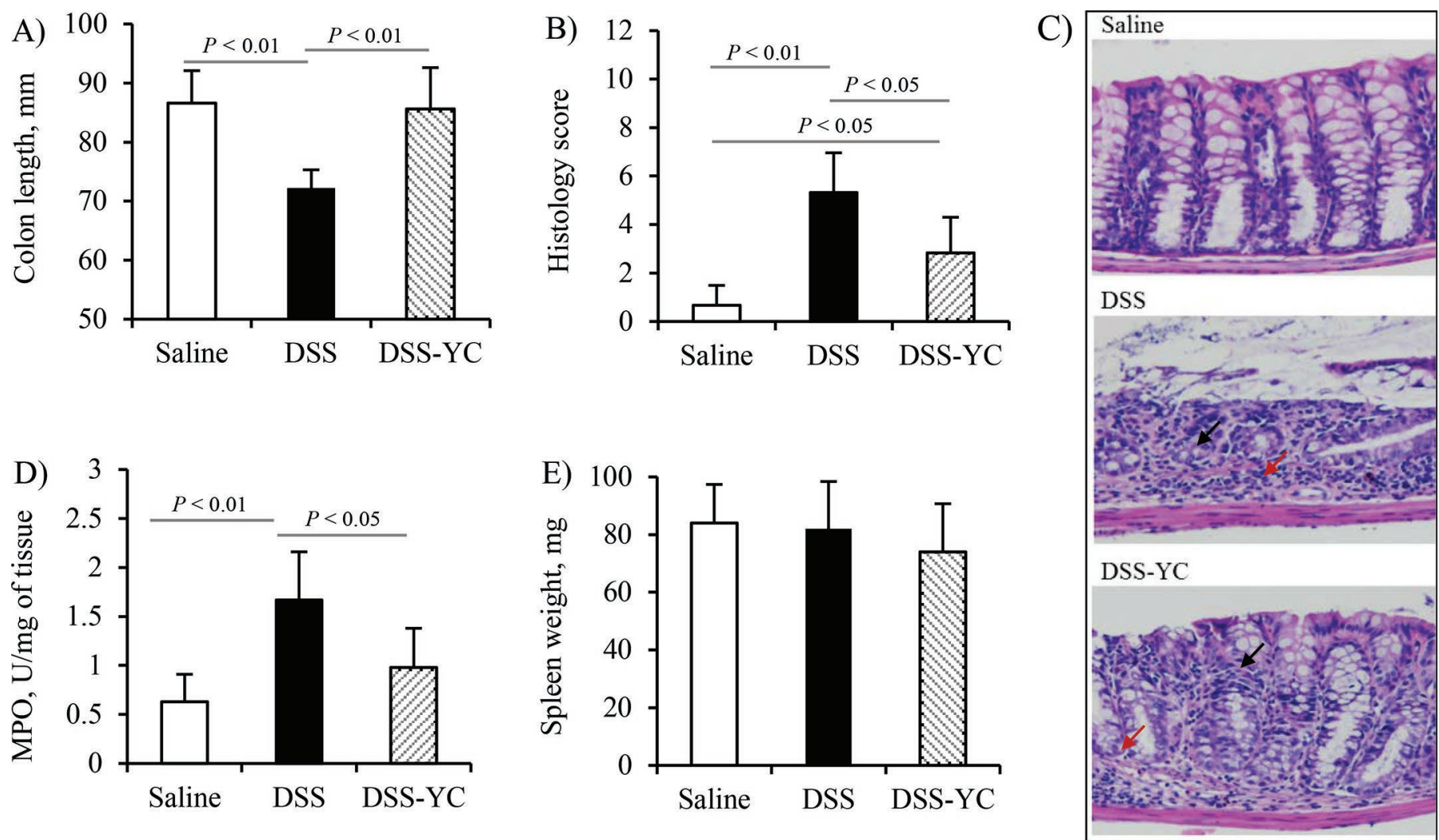

Figure 4. Evaluation of dextran sulfate sodium salt (DSS)-induced colitis in the saline, DSS and DSS-yogurt culture (YC) groups, as measured by (A) changes in colon length, (B) histology score, (D) myeloperoxidase (MPO) activity, and (E) changes in the spleen weight. (C) Examples of extreme changes in hematoxylin and eosin-stained colonic tissue section from healthy (saline) and colitis mice (DSS and DSS-YC). Saline showed normal crypt architecture and the absence of inflammation in colonic mucosa; DSS showed advanced lesions in control colitis mouse, widespread mucosal and submucosal alterations with severe crypt distortion and dense infiltrate of inflammatory cells [black arrow shows crypt distortion and gray (red) arrow shows infiltrate of inflammatory cells]; and DSS-YC showed visible restorative effect of YC-feeding. Saline = healthy control group (without DSS), received saline during intervention; DSS = control colitis group, received saline during intervention; DSS-YC = interventional colitis group, received yogurt culture mixture during intervention. The data are expressed as the means \pm SD. Statistical analysis was performed by $t$ test (A, D, E) and by Mann-Whitney test (B).

The mean values of spleen weight in the tested groups ranged from $74 \pm 17.7$ to $84 \pm 14.4 \mathrm{mg}$ (Figure $4 \mathrm{E}$ ), and we do not have evidence to reject the hypothesis that the means are equal.

\section{S. thermophilus MK10 and L. bulgaricus 151 Modulate Mucosa-Associated Microbiota Profile and Activity}

Table 1 illustrates the number of cultivable bacteria associated with the colonic epithelium of the tested mice. Strict anaerobes and lactobacilli dominated in the tested tissues. The mean counts for the groups were similar and ranged from $6.53 \pm 0.28$ to $6.95 \pm 0.33$ and from $6.30 \pm 0.20$ to $6.97 \pm 0.12 \mathrm{log} \mathrm{cfu} / \mathrm{g}$ tissue for total anaerobes and Lactobacillus spp., respectively; however, DSS administration reduced the Bifidobacterium population and enhanced Enterococcus $(P<0.01)$. The amount of bifidobacteria in the tested samples was the highest in the control saline group and differed from both the DSS- and DSS-YC-receiving mice $(P<0.01$ and $P<0.05$, respectively). Enterococci were not detected in the tested tissue of healthy mice; however, they appeared in both DSS-receiving groups. Mice treated with the YC set possessed epithelium-attached Enterobacteriaceae and yeasts not found in the colonic samples of the remaining animals. We did not detect sulfite-reducing bacteria in any of the tested samples.

As shown in Table 2, the animals differed in the cecal concentration of SCFA. Administration of DSS caused an increase in the total SCFA and putrefactive shortchain fatty acids (PSCFA; $P<0.05$ ). Particularly, acetic, propionic, valeric, and lactic acid concentrations were increased after DSS incorporation. Feeding mice YC lowered valeric acid and isovaleric acid and total PSCFA $(P<0.01)$ to below the level observed in the 
Table 1. Bacterial counts in colon tissue $(\log \mathrm{cfu} / \mathrm{g} \pm \mathrm{SD})^{1,2,3}$

\begin{tabular}{|c|c|c|c|}
\hline Item & Saline & DSS & DSS-YC \\
\hline Total anaerobes & $6.53 \pm 0.28$ & $6.72 \pm 0.37$ & $6.95 \pm 0.33$ \\
\hline Lactobacillus spp. & $6.30 \pm 0.20$ & $6.44 \pm 0.46$ & $6.97 \pm 0.12^{* *}$ \\
\hline Bifidobacterium spp. & $6.10 \pm 0.28$ & $4.89 \pm 0.21^{* *}$ & $5.24 \pm 0.44^{*}$ \\
\hline Enterobacteriaceae & $<0.93$ & $<1.17$ & $2.88 \pm 0.13^{* * *} \# \# \#$ \\
\hline Enterococcus spp. & $<0.93$ & $2.41 \pm 0.33^{* *}$ & $3.17 \pm 0.23^{* * *} \#$ \\
\hline Yeasts & $<0.93$ & $<1.17$ & $3.07 \pm 0.29^{* * *} \# \# \#$ \\
\hline
\end{tabular}

${ }^{1}$ Saline $=$ healthy control group [without dextran sulfate sodium salt (DSS)], received saline during intervention; DSS = control colitis group, received saline during intervention; DSS-YC $=$ interventional colitis group, received yogurt culture mixture during intervention.

${ }^{2}$ The data are expressed as the means $\pm \mathrm{SD}$. Statistical analysis was performed by $t$ test. When necessary, the detection limit was applied for the calculation. ${ }^{*} P<0.05$, ${ }^{* *} P<0.01$, ${ }^{* * *} P<0.001$ in comparison with saline group. \#P<0.05, \#\#\#P $<0.001$ in comparison with DSS group.

${ }^{3}$ There was no sulfite-reducing bacteria on the tested tissues (the detection limit in the DSS-YC group was $0.88 \log \mathrm{cfu} / \mathrm{g})$.

saline group. The profile analysis of the major fatty acids (acetic, propionic, butyric, and lactic) did not reveal differences in the contribution of acetic, propionic, and lactic acids in the total SCFA between the groups. However, the percentage contributions of butyric acid in DSS-administered mice decreased as compared with healthy control $(P<0.05)$. Simultaneously, the ratio of propionic and lactic acids to total SCFA were slightly increased.

\section{S. thermophilus MK10 and L. bulgaricus 151 Regulate the Regulatory T-cell Response}

We performed the B cell ELISpot assay to check total IgA synthesis in the MLN and SPL of the tested mice. Treatment with DSS increased the level of IgA AFC in MLN of the tested animals $(P<0.001$; Figure 5A). Supplementing the diet with the YC set lowered $\operatorname{IgA}$ AFC $(P<0.001$ vs. DSS group $)$ in the MLN of DSS-fed mice; however, the level was still twice as high as in healthy mice ( $P=0.055$ vs. saline group). We found no difference in the amount of IgA AFC in the SPL of the control saline and DSS mice; however, feeding mice with the YC mixture increased IgA synthesis (Figure 5B; $P<0.05$ compared with the saline group).

To further uncover how YC may protect against inflammation and colitis, we analyzed the T-cell population and cytokine profile. We acquired PP, MLN, SPL, and blood for lymphocyte isolation and phenotyping. The percentage of $\mathrm{CD}^{+} \mathrm{CD} 8^{+}$cells was increased in $\mathrm{PP}$ and MLN in all DSS-administered mice $(P<0.01$; Figure 6). However, feeding the DSS-treated animals

Table 2. Concentration and profile of short-chain fatty acids (SCFA) in the cecal digesta (mean \pm SD) $)^{1,2}$

\begin{tabular}{lccc}
\hline Item & Saline & DSS & DSS-YC \\
\hline SCFA, $\mu \mathrm{mol} / g$ of digesta & & & \\
Acetic acid & $94.08 \pm 5.85$ & $131.43 \pm 21.54^{*}$ & $122.70 \pm 19.35$ \\
Propionic acid & $13.52 \pm 2.63$ & $23.67 \pm 2.78^{* *}$ & $22.83 \pm 3.91^{*}$ \\
Butyric acid & $30.12 \pm 2.72$ & $34.37 \pm 2.96$ & $32.99 \pm 3.53$ \\
Valeric acid & $0.93 \pm 0.15$ & $1.60 \pm 0.19^{* *}$ & $0.51 \pm 0.06^{*} \# \# \#$ \\
Isovaleric acid & $1.12 \pm 0.17$ & $1.55 \pm 0.24$ & $0.76 \pm 0.09^{*} \# \#$ \\
Lactic acid & $7.69 \pm 0.92$ & $15.93 \pm 2.16^{* *}$ & $14.32 \pm 2.03^{* *}$ \\
Total PSCFA & $2.05 \pm 0.30$ & $3.15 \pm 0.39^{*}$ & $1.27 \pm 0.05^{*} \# \#$ \\
Total SCFA & $147.46 \pm 10.03$ & $208.55 \pm 24.65^{*}$ & $194.11 \pm 27.94$ \\
Profile, \% of total SCFA & & & \\
Acetic acid & $63.88 \pm 2.41$ & $62.79 \pm 3.04$ & $63.14 \pm 1.27$ \\
Propionic acid & $9.13 \pm 1.33$ & $11.38 \pm 1.01$ & $11.74 \pm 1.00$ \\
Butyric acid & $20.42 \pm 1.15$ & $16.54 \pm 1.01^{*}$ & $17.06 \pm 0.81^{*}$ \\
Lactic acid & $5.20 \pm 0.32$ & $7.77 \pm 1.91$ & $7.39 \pm 0.45$ \\
\hline
\end{tabular}

${ }^{1}$ Saline $=$ healthy control group [without dextran sulfate sodium salt (DSS)], received saline during intervention; DSS = control colitis group, received saline during intervention; DSS-YC = interventional colitis group, received yogurt culture mixture during intervention.

${ }^{2}$ The data are expressed as the means $\pm \mathrm{SD}$. Statistical analysis was performed by $t$ test. ${ }^{*} P<0.05,{ }^{* *} P<0.01$ in comparison with saline group. \#\#P $<0.01$, \#\#\#P $<0.001$ in comparison with DSS group.

${ }^{3} \mathrm{PSCFA}=$ putrefactive short-chain fatty acids (the sum of isovaleric and valeric acids). 
A)

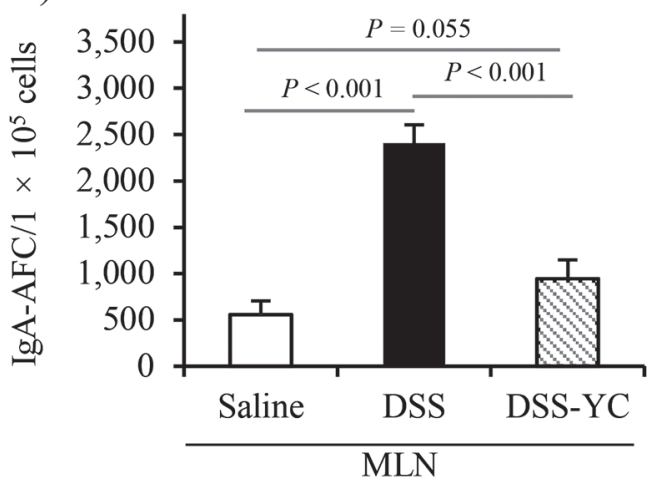

B)

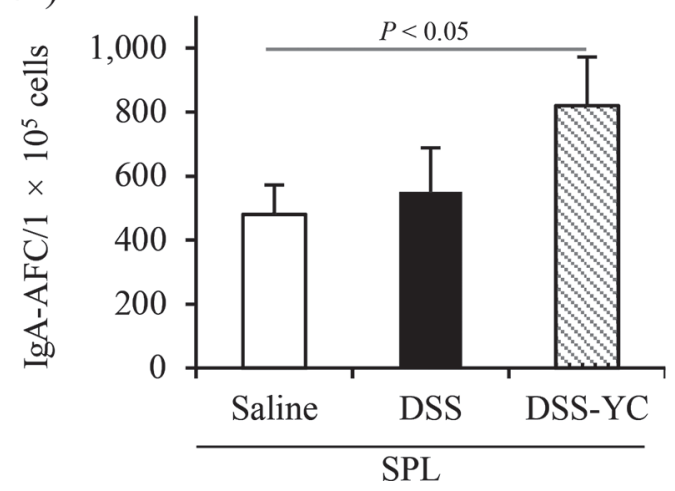

Figure 5. Immunoglobulin A antibody-forming cells (AFC) in (A) mesenteric lymph nodes (MLN) and (B) spleens (SPL) of saline-, dextran sulfate sodium salt (DSS)-, and DSS-yogurt culture (YC)-treated mice. Saline = healthy control group (without DSS), received saline during intervention; DSS = control colitis group, received saline during intervention; DSS-YC = interventional colitis group, received yogurt culture mixture during intervention. The data are expressed as the means \pm SD. Statistical analysis was performed by $t$ test.

with the $\mathrm{YC}$ set lowered the level of $\mathrm{CD} 3^{+} \mathrm{CD} 8^{+}$cells in $\mathrm{PP}(P<0.01$ vs. the DSS group $)$. A similar trend in the $\mathrm{PP}$ occurred in the case of $\mathrm{CD} 3^{+} \mathrm{CD} 4^{+}$cells; however, we found no evidence to reject the hypothesis that the mean values of $\mathrm{CD}^{+} \mathrm{CD}^{+}$are equal in the MLN, SPL, and PBMC. Treatment with DSS did not influence the $\mathrm{CD} 3{ }^{+} \mathrm{CD} 4{ }^{+} \mathrm{CD} 25^{+}$population; however, this population was decreased in $\mathrm{PP}$ and increased in SPL after $\mathrm{YC}$ administration $(P<0.05$ and $P<$ 0.01 vs. both groups, respectively). The contribution of $\mathrm{CD}_{3}{ }^{+} \mathrm{CD} 4^{+} \mathrm{CD} 25^{+} \mathrm{Foxp}^{+}$Tregs in PP, in turn, was clearly the highest in the DSS group (5- and 28 -fold vs. the saline and DSS-YC groups, respectively, $P<0.01$ ) and lowest in the DSS-YC-treated mice. We observed a decrease in this population in the MLN of DSS-administered mice; however, it was greater in the DSS-YC group (7- to 9-fold vs. DSS and saline groups, respectively; $P<0.01)$. The differences almost disappeared in SPL, whereas in PBMC significant enlargement of the $\mathrm{CD} 3{ }^{+} \mathrm{CD} 4^{+} \mathrm{CD} 25^{+} \mathrm{Foxp}^{+}$population in DSS-YC mice was observed compared with both the saline and DSS groups (4- and 8-fold compared with the saline and DSS mice, respectively; $P<0.01$ ).

\section{S. Thermophilus MK10 and L. Bulgaricus 151 Modify Cytokine Secretion}

We performed cytokine profiling to analyze the effect of $\mathrm{YC}$ on the production of physiologically relevant cytokine proteins (IL-2, IL-4, IL-6, IL-10, IL-17A, IFN- $\gamma$, and TNF) and check the direction of T-cell differentiation and polarization (Th1, Th2, or Th17 response). In the serum, the DSS itself caused the enhancement of the concentration of IFN- $\gamma$ (nearly 2 -fold, $P<0.05$ vs. saline group), and decreased the concentration of IL-10 (nearly 5-fold; $P<0.01$; Figure 7A). Feeding DSS-administered mice the YC mixture downregulated IFN- $\gamma$ and increased the concentration of IL-2 (almost 14-fold compared with both saline and DSS groups, $P$ $<0.01)$.

To clarify the immunomodulatory effect of the YC mixture, we further examined cytokine production by MLN and SPL in vitro, after preincubation of the isolated lymphocytes in culture medium. As showed in Figure $7 \mathrm{~B}$ and $7 \mathrm{C}$, the tested animals differed in cytokine secretion by both MLN and SPL. Predominantly, cultures revealed increased levels of interleukin in the YC-administered mice compared with those in the saline and DSS groups. In MLN, however, IL-6 reached the highest level in the DSS group, 2-fold higher versus the saline group $(P<0.05$; Figure 7B). Simultaneously increased level of IL-4 was noted in these mice (5-fold, $P<0.05)$. Out of the remaining cytokines tested, we found no significant difference in IL-6 concentration between the saline and DSS-YC groups; the level of IL-10 did not change whatsoever, whereas the levels of IL-17A, TNF, IFN- $\gamma$, IL-4, and IL-2 were the highest in the DSS-YC group and increased 4-, 6-, 5-, 10-, and 25fold, respectively, against the saline group $(P<0.05)$. Likewise, in the SPL cultures, the highest secretion of cytokine proteins was noted in the DSS-YC group (Figure 7C). The tested cytokines, IL-10, IL-17A, TNF, IFN- $\gamma$, IL-6, IL-4, and IL-2, increased about 25-, 3-, 4-, 19-, 3-, 30-, and 8-fold, respectively, as compared with the saline group $(P<0.05)$. Administration of DSS alone increased IL-10 (2-fold) and IL-4 (10-fold) secretion and decreased the level of TNF (3-fold; $P<$ 0.05 vs. saline group). 

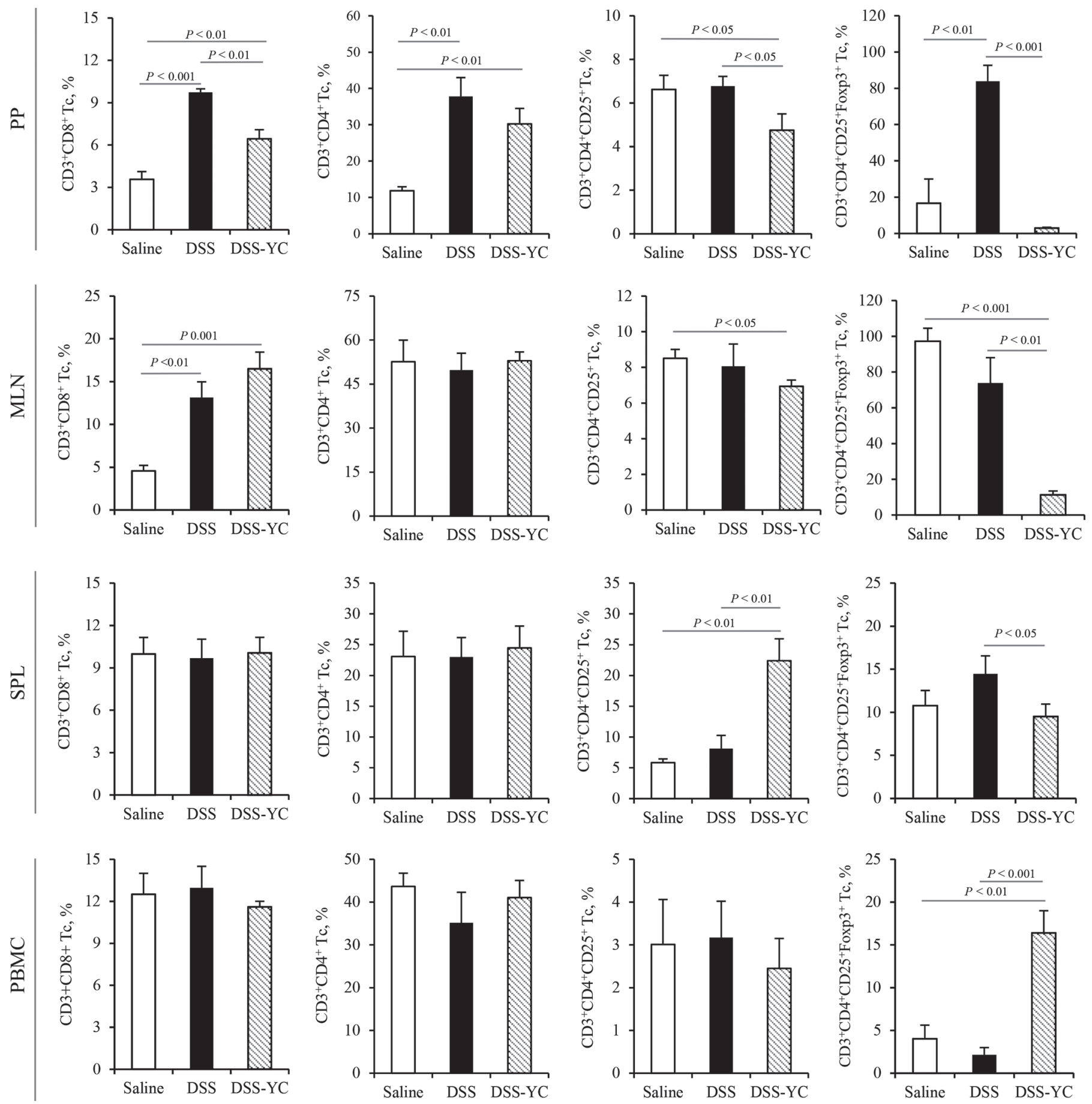

Figure 6. Distribution of T-cell (Tc) subsets in Peyer's patches (PP), mesenteric lymph nodes (MLN), spleens (SPL), and peripheral blood mononuclear cells (PBMC) of saline-, dextran sulfate sodium salt (DSS)-, and DSS-yogurt culture (YC)-treated mice. Saline = healthy control group (without DSS), received saline during intervention; DSS = control colitis group, received saline during intervention; DSS-YC $=$ interventional colitis group, received yogurt culture mixture during intervention. The data are expressed as the means \pm SD. Statistical analysis was performed by $t$ test. 


\section{DISCUSSION}

Feeding mice for a few days with DSS polymers in the drinking water induces a very reproducible acute
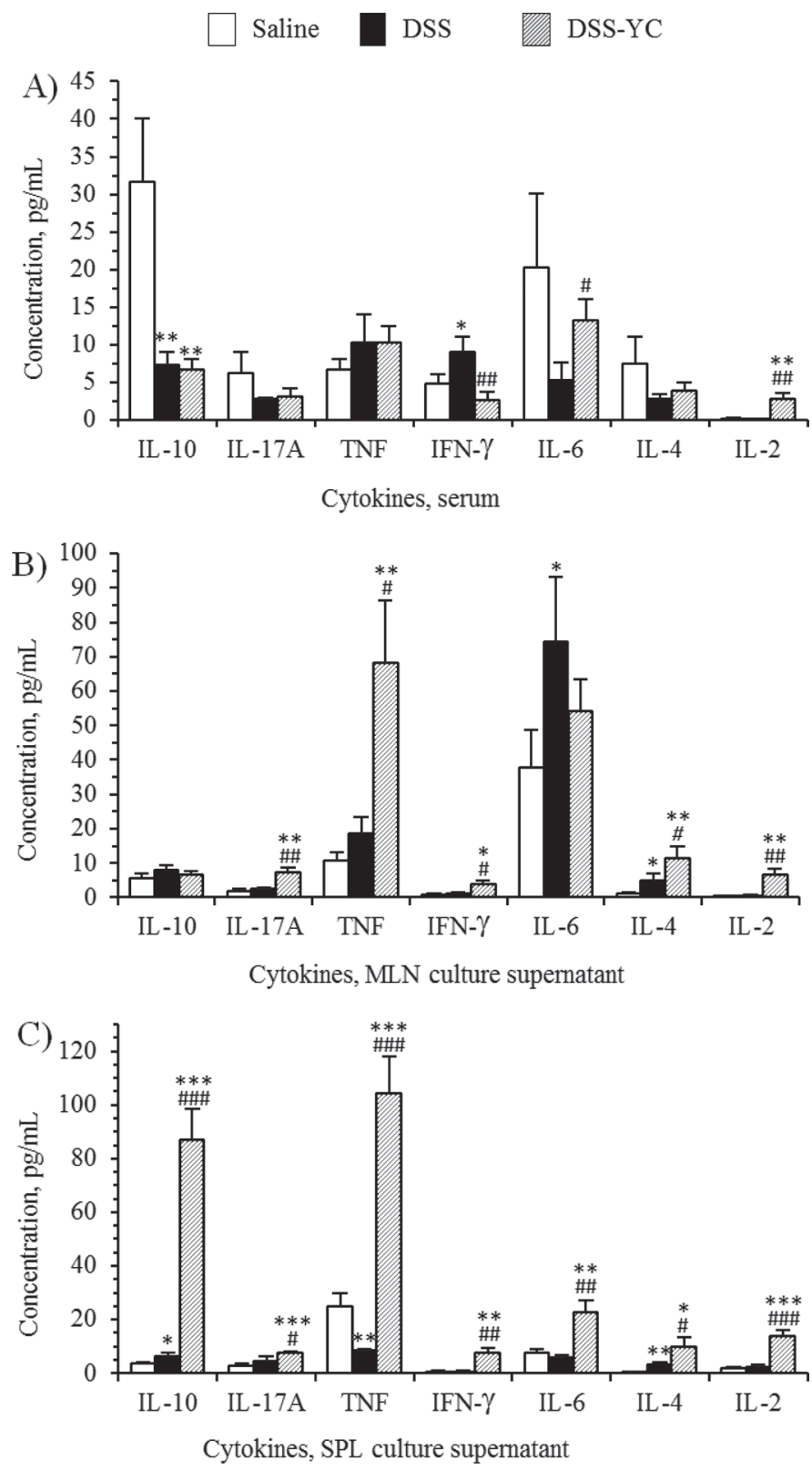

Figure 7. Cytokine profile in saline-, dextran sulfate sodium salt (DSS)-, and DSS-yogurt culture (YC)-treated mice measured in serum (A) or secreted by $\mathrm{T}$ cells isolated from mesenteric lymph nodes (MLN) and spleens (SPL) of the tested animals and preincubated for $4 \mathrm{~d}$ in vitro (B and C). Saline = healthy control group (without DSS), received saline during intervention; DSS $=$ control colitis group, received saline during intervention; DSS-YC $=$ interventional colitis group, received yogurt culture mixture during intervention. The data are expressed as the means \pm SD. Statistical analysis was performed by $t$ test. ${ }^{*} P<0.05,{ }^{* *} P<0.01,{ }^{* * *} P<0.001$ in comparison with saline group. $\# P<0.05$, \#\#P $<0.01$, \#\#\#P $<0.001$ in comparison with DSS group. colitis characterized by weight loss, bloody diarrhea, and histological damage of the intestine (Kim et al., 2012; Rose et al., 2012). We demonstrated that the S. thermophilus MK-10 and L. bulgaricus 151 set attenuated the clinical symptoms of DSS-induced colitis in mice, such as reduced BW loss, decreased DAI and MPO activity, and upregulated colon length, compared with those in the control colitis mice. The mechanism by which DSS induces inflammation is unclear, as much of the acute inflammatory response induced by DSS likely arises from the nonspecific disruption or injury of the basolateral intercellular space of the colonic epithelium (Koboziev et al., 2011). We observed upregulation of colon length and measurably reduced damage of the mucosa caused by DSS in the YC-administered mice, what probably, to some extent, sustained the integrity of the epithelium (Figure 4B and 4C). Evidence exists that the intestinal bacteria and probiotics may change the expression and distribution of tight junction proteins or alleviate oxidative stress and thus strengthen the intestinal barrier; for example, the nonpathogenic Escherichia coli Nissle 1917 strain, which appeared to be safe and effective in maintenance of clinical remission of ulcerative colitis in humans (Ukena et al., 2007; Wasilewska et al., 2018). Putt et al. (2017) described the improving effect, dependent on digestion, of standard yogurt on barrier integrity in the Caco-2 cell model. Oxidative stress can lead to damage of the mucosa and bacterial invasion, and further to inappropriate activation of immune signaling pathways and inflammation. We observed lowered activity of MPO, a protein released into the phagosome of neutrophils during the degranulation process, which when overexpressed can damage normal tissue and contribute to inflammation. Ito et al. (2008) tested $2 S$. thermophilus strains and found that only one, S. thermophilus YIT 2001, displaying high antioxidative activity, prevented oxidative injury to the colonic mucosa and improved the disease activity index in DSS-induced colitis in mice. We observed accelerated healing in the $\mathrm{YC}$-administered mice, but the DSS-induced injury patterns and changes within the colonic mucosa and muscular compartment contributed to colonic dysregulation, resulting in immunological and microbiological alterations.

Little information exists concerning the structure and function of bacterial biofilms in the large intestine. One of the risk factors for IBD development is that the mucus layer overlaying the epithelium becomes more permeable to bacteria and bacterial products (Johansson et al., 2014). The inner colon mucus layer overlaying the epithelium poses a barrier separating the body from the external environment and is impenetrable to bacteria in the healthy gut. Defects in this system may trigger inflammation and extensive bacterial contact 
that may consequently cause leakage into the tissue. Particularly, during dysbiosis, some pathogenic bacteria can pass across the epithelium and penetrate the host's body. An intense load of microbes in turn can pose a burden on the immune system. In our study, the total amount of the intestine-associated microbiota did not change significantly; however, appreciable variations occurred in the number of cells of the tested bacterial groups. The DSS itself considerably decreased bifidobacteria and enlarged enterococci, whereas feeding mice with $\mathrm{YC}$ enhanced not only tissue-associated enterococci but also Enterobacteriaceae and yeasts not detected in the remaining groups. We do not know if it was an increase in the amount of microbes bound to the colonic epithelium or the ones that penetrated the epithelial barrier and pass into intestinal tissue or both; however, we observed upregulation of colon length with decreased MPO activity and lowered crypt distortion. Thus, in this case, the microbes associated with the colonic intestine seem to have a rather supportive and not detrimental effect. We found no microbes translocated across the intestinal barrier of the DSS-YC mice in blood, MLN, and other organs (E. Wasilewska, unpublished data). Bailey et al. (2017) showed that S. thermophilus NCIMB 41856 delayed onset of colitis and reduced clinical signs of disease in a DSS-colitis mouse model. Those authors did not observe a difference in the amount of microbes attached to the colonic epithelium between DSS and DSS $+S$. thermophilus treated mice, but the $S$. thermophilus NCIMB 41856 strain reduced amount of microbes crossing mucosal and cellular epithelial barrier.

Composition of the epithelium-associated microbiota communities is probably determined by a variety of host factors, such as immunity and IgA and defensins secretion, mucus composition, turnover rate of the epithelial cells, intestine motility, availability of adhesion sites, or colonization resistance mediated by composition of the luminal gut microbiota. Normal resident bacterial communities in the healthy gut are highly diversified, with predominance of Firmicutes and Bacteroidetes and low concentration of Enterobacteriaceae. Dysbiosis in IBD patients is characterized by decreased biodiversity and expansion of Enterobacteriaceae and certain Clostridium subsets (Lane et al., 2017; Wasilewska and Wroblewska, 2018). Banerjee et al. (2009) showed that Lactobacillus delbrueckii ssp. bulgaricus B-30892 reduced colonization and Clostridium difficile mediated cytotoxicity in Caco-2 model. Injured mucosa and enhanced exfoliation of the inflamed cells expose new binding sites for luminal microbiota and create chance for rearrangements in intestinal biofilm structure, depending probably on a variety of other circumstances. Feeding mice a YC mixture promoted members of epitheliumassociated Firmicutes (lactobacilli, bifidobacteria, and enterococci, to varying degrees) but also enterobacteria and yeasts. All of these microbes possess high binding affinity for epithelial cell membranes (Boudeau et al., 2003; Swidsinski et al., 2008; Wasilewska et al., 2010; Christoffersen et al., 2012; Sengupta et al., 2013; Richardson et al., 2018). Enterococci increased in both DSS groups; however, enterobacteria and yeasts increased only in the mice administered YC mixture. We do not know if the effect is stable and positive in the long run, but we can speculate that in the case in question the attached cells are beneficial for the host and exert a protective effect due to observed clinical symptoms. The YC tested could act antagonistically and suppress opportunistic pathogenic microbes, as these strains were specially selected based on their antagonistic effect toward some pathogenic E. coli and Staphylococcus aureus strains (Bielecka et al., 1994a,b). On the other hand, bacteria adjacent to the epithelium could protect against the adhesion and invasion of resident luminal pathogens (Boudeau et al., 2003). Moreover, the cellattached bacteria may be quickly exfoliated together with damaged cells or may persist on the epithelium for some time if the cell is, for example, in an intensified repair process, as was probably the case of DSS-YC mice. Nonpathogenic Enterococcus strains may produce antimicrobials (e.g., enterocin) and block adhesion sites for pathogens, such as enterotoxigenic E. coli; similarly, yeast may exert protective effect. Saccharomyces boulardii (subtype of Saccharomyces cerevisiae) also possess the therapeutic potential for ulcerative colitis and even Crohn's disease management, especially when combined with baseline medical therapy (Wasilewska and Wroblewska, 2018). On the other hand, excessive proliferation of $S$. boulardii can cause candidiasis and even sepsis. Antibodies against $S$. cerevisiae are detectable in the serum of patients with Crohn's disease and have been proposed as one of the serological markers for Crohn's disease diagnosis (Bertin et al., 2013).

We measured the concentration of SCFA to evaluate changes in bacterial metabolic activity in the gut; SCFA are main bacterial metabolites with anti-inflammatory properties that play a role in protecting intestinal integrity. Many studies have indicated that SCFA exhibit a wide range of physiological function, including T-cell polarization and induction (Smith et al., 2013; Levy et al., 2016). The role of butyrate as a major energy source for epithelial cells, regulating their gene expression, proliferation, differentiation, and apoptosis is well recognized (Topping and Clifton, 2001; Kim et al., 2014). Di Sabatino et al. (2005) showed the high antiinflammatory effect of butyrate in experimental colitis 
and Crohn's disease lamina propria cells in vitro. Our cultures did not change butyrate concentration, but they generally downregulated SCFA in mice administered DSS, especially the concentrations of putrefactive valeric and isovaleric acids and total PSCFA. Valeric, isovaleric, and isobutyric acids are primarily produced from the catabolism of proteins, particularly from branched AA fermentation (Cardona et al., 2005). Cardona et al. (2005) found a strong correlation between isobutyric and isovaleric acids in the gut of different species irrespective of age, diet, and living conditions, probably due to the microbial breakdown of intestinal sloughed cells. The observed increased amounts of isovaleric and valeric acids in the control colitis group may result from enhanced exfoliation of the inflamed epithelium cells and intensified bacterial proteolytic activity that, in turn, may exacerbate inflammation. One of the suggested mechanisms that tie an intestinal dysbiosis to the pathophysiology of IBD involves the release of enteric bacterial proteases that interact with protease-activated receptors on epithelial cells, resulting in intestinal barrier dysfunction and exposure of the enteric immune system to luminal antigens (Carroll and Maharshak, 2013). Thus, the observed decline of putrefactive acids in the DSS-YC mice seems to confirm protective effect of the tested cultures on the inflammatory process.

An intestinal barrier separates the gut lumen from the inner host and consists of mechanical (mucus, epithelial layer), humoral (defensins, IgA), immunological (lymphocytes, innate immune cells), and muscular and neurological elements that prevent the entry of pathogenic microorganisms and toxic luminal substances into the body (Bischoff et al., 2014). Mucosal surfaces and the mucosa-associated lymphoid tissues are in continuous contact and crosstalk with gut microbiota. Thus, they function to distinguish between commensal and pathogenic microbes to control the latter. Many probiotics and prebiotics were shown to modulate the intestinal mucosal and systemic immune system (Ashraf and Shah, 2014). Except for the amelioration of clinical symptoms, we investigated the effect of the tested YC on the immune system and regulatory T-cell response. Using flow cytometry, we analyzed T-cell populations in PP, MLN, SPL and PBMC, as well as the Th1/Th2/ Th17 cytokine profile secreted by MLN and SPL and in the serum of the tested mice; we also assessed IgA AFC in MLN and SPL to check the activity of B cells. The animals fed DSS showed significantly higher levels of helper $\mathrm{CD} 4^{+} \mathrm{T}$ cells in $\mathrm{PP}$ and cytotoxic $\mathrm{CD} 8^{+} \mathrm{T}$ cells in PP and MLN, most probably due to intensified activity of antigen-presenting cells and further activation of cytotoxic $\mathrm{CD} 8^{+}$and naïve helper $\mathrm{CD} 4^{+} \mathrm{T}$ lymphocytes.
Such activated $\mathrm{T}$ cells secrete cytokines (IFN- $\gamma$, IL-2, IL-4, and others) that activate their differentiation into functional Th1, Th2, Th17, and Treg subsets or effector Tc cells, such as macrophages. Cytotoxic T cells kill abnormal or infected cells and, once activated, proliferate with the help of many regulatory cytokines. In MLN, we observed increased levels of IL- 6 and IL- 4 in the DSS group and increased levels of IL-2, IL-4, IFN- $\gamma$, IL$17 \mathrm{~A}$, and TNF in mice administered YC. Some of the increases may be driven from the apoptotic or cytotoxic action of activated effector $\mathrm{CD} 8^{+} \mathrm{T}$ cells, and others from activated Th0 cells (Chávez-Galán et al., 2009; Shrikant et al., 2010; Hamada et al., 2013). Interleukin-6 is a proinflammatory cytokine that, among other traits, stimulates B lymphocytes proliferation, whereas IL-4 stimulates microphages differentiation as well as a Th2 response and differentiation of $\mathrm{B}$ lymphocytes into plasma cells secreting antibodies, both probably increased amount of IgA-AFC in the DSS group. The administration of the $\mathrm{YC}$ mixture downregulated $\mathrm{CD} 8^{+}$ cells in PP, probably due to better gut microbiota balance and less extensive inflammation-mediated damage in the colonic tissue, but also due to generally enhanced immune response and healing. Gobbato et al. (2008) demonstrated the anti-inflammatory effect of yogurt in 2,4,6-trinitrobenzene sulfonic acid (TNBS)-induced colitis, which was related to an increase in the number of the $\mathrm{IgA}^{+}$cells, a decrease in $\mathrm{CD}^{+}$population, and an increased apoptosis of the infiltrative cells in the colonic tissue, which essentially accelerated regeneration of the colonic epithelium. However, mice in Gobbato et al. (2008) were fed yogurt before and after TNBS administration, and although an increased number of IgA-producing cells in the large intestine was observed, the effect was visible in the course of TNBS administration and not in the course of yogurt feeding. Our studies revealed increase in the IgA AFC in SPL and, by extension, this seems to confirm the stimulating effect of $\mathrm{YC}$ on $\mathrm{Ig} \mathrm{A}$ secretion in mice with colitis.

Treatment with YC significantly increased the level of $\mathrm{CD}^{+}{ }^{+} \mathrm{CD} 4^{+} \mathrm{CD} 25^{+}$cells in splenocytes. Natural $\mathrm{CD} 4^{+} \mathrm{CD} 25^{+}$Tregs are critical to maintain immune homeostasis (Ng et al., 2001; Barnes and Powrie, 2009), as they possess anti-inflammatory properties. Thus, an increase in Tregs can aid in the control of clinical manifestations. Regulatory $\mathrm{T}$ cells work through cytokine intermediaries such as TGF- $\beta$ and IL-10, both of which mostly inhibit the immune system, and via a direct cell to cell contact (Glick et al., 2013). We observed the increased input of $\mathrm{CD} 33^{+} \mathrm{CD} 4^{+} \mathrm{CD} 25^{+}$cells combined with increased IL-10 secretion in splenic lymphocytes of mice administered DSS-YC. The IL-10 produced by Tregs controls inflammatory responses to self and nonself an- 
tigens (Vieira et al., 2004). Evidence exists that SCFA play a role in the regulating the gut-associated lymphoid tissue (Smith et al., 2013; Morrison and Preston, 2016). Microbiota-specific Tregs in the colon can be regulated by SCFA that signal through the G protein-coupled receptor GPR43 (Maslowski et al., 2009). Generally, intestinal homeostasis is maintained by regulatory $\mathrm{T}$-cell populations consisting of 2 major $\mathrm{CD}^{+}$cell subsets, Foxp $^{+}$and Tr1-like cells, that produce IL-10 (Barnes and Powrie, 2009). The increased IL-10 production correlates with the ability to reduce the inflammatory response associated with colitis (Glocker et al., 2011). del Carmen et al. (2015) enhanced the S. thermophilus therapeutic activity in an acute colitis model through incorporation into the strain of the therapeutic cDNA delivery plasmid, enhancing IL-10 production.

To identify the developmental capacity of CD $4^{+} \mathrm{CD} 25^{+}$ cells, we analyzed the levels of $\mathrm{CD} 4^{+} \mathrm{CD} 25^{+} \mathrm{Foxp} 3^{+} \mathrm{T}$ cells. Adaptive Foxp $3^{+} \mathrm{CD} 4^{+}$regulatory $\mathrm{T}$ cells are driven by the need to maintain a noninflammatory environment in the gut, to suppress the immune response to allergens, and to decrease chronic inflammation (Curotto de Lafaille and Lafaille, 2009). The DSS itself did not change the frequency of $\mathrm{CD} 3{ }^{+} \mathrm{CD} 4^{+} \mathrm{CD} 25^{+}$ in the tested samples, but significantly increased the frequency of $\mathrm{CD} 3^{+} \mathrm{CD} 4^{+} \mathrm{CD} 25^{+} \mathrm{Foxp} 3^{+}$in $\mathrm{PP}$, which was probably due to an intensified load of antigens nearby the intestine that pose a burden on the immune system and necessity of enhanced regulation by antigen presenting cells. The effect was different in MLN, where DSS administration did not influence the level of $\mathrm{CD} 3{ }^{+} \mathrm{CD} 4^{+} \mathrm{CD} 25^{+}$Foxp $3^{+}$Tregs; however, we found a significant increase in IL-6 concentration and cytotoxic $\mathrm{CD} 8^{+} \mathrm{T}$ cells and IgA AFC appeared. Interleukin-6 is an important mediator of fever and the acute phase response, and also supports the growth of B cells and acts antagonistically to regulatory cells. Evidence exists that proinflammatory cytokine IL-6 plays a crucial role in the uncontrolled intestinal inflammatory process (Atreya and Neurath, 2005). Opposite DSS, the YC mixture significantly decreased $\mathrm{CD} 3{ }^{+} \mathrm{CD} 4^{+} \mathrm{CD} 25^{+} \mathrm{Foxp} 3^{+}$Tregs in MLN. It also suppressed pro-inflammatory IL-6 secretion, clearly enhanced IL-2 and IL-4 regulatory cytokines, and increased IL-17A, IFN- $\gamma$, and TNF secretion, thus generally enhancing immune activity and healing process by modulating Th1/Th2/Th17 cells response. In turn, the lowered IgA production took place in DSS-YC mice, likely due to the therapeutic effect of the administered bacteria resulting in decreased inflammation. However, ingestion of S. thermophilus MK-10 and L. bulgaricus 151 increased the IgA AFC in SPL of DSS-YC-treated mice, concurrent with a significant elevation of $\mathrm{CD} 3{ }^{+} \mathrm{CD} 4{ }^{+} \mathrm{CD} 25^{+}$cells, which are critical in healing and in the maintenance of self-tolerance and the prevention of autoimmune disease ( $\mathrm{Ng}$ et al., 2001; Barnes and Powrie, 2009). We observed no such effect in the MLN of DSS-treated mice, where YC downregulated the expression of IgA AFC, although the level remained high. In SPL, the YC mixture downregulated the expression of $\mathrm{CD} 3{ }^{+} \mathrm{CD} 4{ }^{+} \mathrm{CD} 25^{+}$Foxp3 cells, likely due to the therapeutic effect of the administered bacteria.

The differentiation, migration, and maintenance of intestinal Tregs are controlled by specific signals from the local environment; in particular, intestinal microbiota provides antigens and immunomodulatory molecules that modulate intestinal Tregs expression (Tanoue et al., 2016). Evidence exists that propionate administration increased the expression of Foxp3 and IL-10 in colonic Tregs (Smith et al., 2013). We observed the increased propionic acid concentration in both DSS and DSS-YC groups; however, only the DSS group showed increased Foxp $3^{+}$Tregs in PP, probably due intensified barrier dysfunction and direct exposure to environmental antigens. Simultaneously, a significant increase in IgA AFC was observed in the control DSS mice. The tested YC mixture improved microbial balance and downregulated inflammatory cytokine secretion and the Th2 response in MLN and enhanced Th1/Th2/ Th17 polarization in SPL. In particular, the expression of regulatory IL-10, IL-2, IL-4, IFN- $\gamma$, and TNF in SPL seem to be enlarged by the YC mixture. Tumor necrosis factor- $\alpha$ is well known for its proinflammatory activity in various diseases, including IBD; however, in our study, the mean serum TNF levels were similar for all groups. In addition, we found no spleen enlargement in the tested mice (Figure 4E). Evidence exists that TNF suppresses the pathogenesis of acute intestinal inflammation by promoting local steroidogenesis (Noti et al., 2011). Naito et al. (2003) found significantly enhanced DSS-induced inflammation in $\mathrm{TNF}-\alpha^{-/-}$mice compared with that in $\mathrm{TNF}-\alpha^{+/+}$mice. The regulatory effect of the S. thermophilus MK-10 and L. bulgaricus 151 set on cytokine expression was also visible in serum; however, the lowered level of IL-10 was observed in all DSS administered mice but the level of proinflammatory IFN- $\gamma$ was downregulated and the levels of the remaining cytokines were similar for saline- and YCadministered mice, except for the enhanced amount of regulatory IL-2. Interleukin-2 plays an important role in the development and expansion of effector $\mathrm{T}$ cells and is critical for the establishment and maintenance of immune tolerance, as it regulates Foxp3 expression in $\mathrm{CD} 4^{+} \mathrm{CD} 25^{+}$regulatory $\mathrm{T}$ cells (Zorn et al., 2006). 


\section{CONCLUSIONS}

Our data provide evidence that $S$. thermophilus MK10 and L. bulgaricus 151 exert therapeutic effects on DSS-induced colitis in mice. We demonstrated that the strains improved mucosal healing. A significant increase in BW and colon length and a decrease in the DAI scores and MPO activity were observed in DSS mice after feeding with the tested YC. The mechanism of healing could be activated through direct and indirect effects on the gut microbiota balance and activity and epithelium-attached microbes, causing changes in local and systemic immunity. The observed therapeutic effect of S. thermophilus MK-10 and L. bulgaricus was mediated through modulation of T-helper-cell subset activities (Th1/Th2/Th17) and Tregs response, by improving colonic healing and downregulation of $\mathrm{CD} 3^{+} \mathrm{CD} 4^{+} \mathrm{CD} 25^{+} \mathrm{Foxp}^{+} \mathrm{T}$ cells in the intestine but enhancement in peripheral lymphoid organs.

\section{ACKNOWLEDGMENTS}

This research was supported by the National Science Centre, Krakow, Poland, and project 2011/01/B/ NZ9/07136.

\section{REFERENCES}

Ashraf, R., and N. P. Shah. 2014. Immune system stimulation by probiotic microorganisms. Crit. Rev. Food Sci. Nutr. 54:938-956. https://doi.org/10.1080/10408398.2011.619671.

Atreya, R., and M. F. Neurath. 2005. Involvement of IL-6 in the pathogenesis of inflammatory bowel disease and colon cancer. Clin. Rev. Allergy Immunol. 28:187-196. https://doi.org/10.1385/Criai:28:3: 187.

Bailey, J. R., V. Vince, N. A. Williams, and T. A. Cogan. 2017. Streptococcus thermophilus NCIMB 41856 ameliorates signs of colitis in an animal model of inflammatory bowel disease. Benef. Microbes 8:605-614. https://doi.org/10.3920/BM2016.0110.

Banerjee, P., G. J. Merkel, and A. K. Bhunia. 2009. Lactobacillus delbrueckii ssp. bulgaricus B-30892 can inhibit cytotoxic effects and adhesion of pathogenic Clostridium difficile to Caco-2 cells. Gut Pathog. 1:8. https://doi.org/10.1186/1757-4749-1-8.

Barnes, M. J., and F. Powrie. 2009. Regulatory T cells reinforce intestinal homeostasis. Immunity 31:401-411. https://doi.org/10.1016/ j.immuni.2009.08.011.

Berg, D., J. C. Clemente, and J. F. Colombel. 2015. Can inflammatory bowel disease be permanently treated with short-term interventions on the microbiome? Expert Rev. Gastroenterol. Hepatol. 9:781-795. https://doi.org/10.1586/17474124.2015.1013031.

Bertin, D., J. C. Grimaud, N. Lesavre, C. Benelmouloud, A. Desjeux, S. Garcia, and S. Desplat-Jego. 2013. Targeting tissular immune response improves diagnostic performance of anti-Saccharomyces cerevisiae antibodies (ASCA) in Crohn's disease. PLoS One 8:e80433. https://doi.org/10.1371/journal.pone.0080433.

Bielecka, M., and A. Majkowska. 2000. Effect of spray drying temperature of yoghurt on the survival of starter cultures, moisture content and sensoric properties of yoghurt powder. Nahrung 44:257-260. https://doi.org/10.1002/1521-3803(20000701)44:4<257::AIDFOOD257>3.0.CO;2-E.
Bielecka, M., A. Majkowska, and E. Biedrzycka. 1994a. Selection of strain for yogurt starters regarding their antibacterial properties. Pol. J. Food Nutr. Sci. 3/44:51-61.

Bielecka, M., A. Majkowska, and E. Biedrzycka. 1994b. Synergistic yogurt cultures with antibacterial properties. Pol. J. Food Nutr. Sci. 3/44:63-73.

Bielecka, M., A. Majkowska, E. Biedrzycka, and El. Biedrzycka. 2000. Microbiological changes in modified yoghurts during manufacture and storage. Prog. Biotechnol. 17:283-289. https://doi.org/10 .1016/S0921-0423(00)80081-7.

Bischoff, S. C., G. Barbara, W. Buurman, T. Ockhuizen, J. D. Schulzke, M. Serino, H. Tilg, A. Watson, and J. M. Wells. 2014. Intestinal permeability-A new target for disease prevention and therapy. BMC Gastroenterol. 14:189. https://doi.org/10.1186/ s12876-014-0189-7.

Boudeau, J., A.-L. Glasser, S. Julien, J.-F. Colombel, and A. Darfeuille-Michaud. 2003. Inhibitory effect of probiotic Escherichia coli strain Nissle 1917 on adhesion to and invasion of intestinal epithelial cells by adherent-invasive E. coli strains isolated from patients with Crohn's disease. Aliment. Pharmacol. Ther. 18:4556. https://doi.org/10.1046/j.0269-2813.2003.01638.x.

Buckner, J. H. 2010. Mechanisms of impaired regulation by $\mathrm{CD}^{+} \mathrm{CD} 25^{+} \mathrm{FOXP}^{+}{ }^{+}$regulatory $\mathrm{T}$ cells in human autoimmune diseases. Nat. Rev. Immunol. 10:849-859. https://doi.org/10 $.1038 /$ nri2889.

Cardona, M. E., E. Collinder, S. Stern, B. Tjellström, E. Norin, and T. Midtvedt. 2005. Correlation between fecal iso-butyric and iso-valeric acids in different species. Microb. Ecol. Health Dis. 17:177-182. https://doi.org/10.1080/08910600500356265.

Carroll, I. M., and N. Maharshak. 2013. Enteric bacterial proteases in inflammatory bowel disease - Pathophysiology and clinical implications. World J. Gastroenterol. 19:7531-7543. https://doi.org/10 .3748/wjg.v19.i43.7531.

Chávez-Galán, L., M. C. Arenas-Del Angel, E. Zenteno, R. Chavez, and R. Lascurain. 2009. Cell death mechanisms induced by cytotoxic lymphocytes. Cell. Mol. Immunol. 6:15-25. https://doi.org/ $10.1038 / \mathrm{cmi} .2009 .3$.

Christoffersen, T. E., H. Jensen, C. R. Kleiveland, G. Dorum, M. Jacobsen, and T. Lea. 2012. In vitro comparison of commensal, probiotic and pathogenic strains of Enterococcus faecalis. Br. J. Nutr. 108:2043-2053. https://doi.org/10.1017/S0007114512000220.

Curotto de Lafaille, M. A., and J. J. Lafaille. 2009. Natural and adaptive Foxp $3^{+}$regulatory $\mathrm{T}$ cells: more of the same or a division of labor? Immunity 30:626-635. https://doi.org/10.1016/j.immuni 2009.05.002.

de Assis, P. O. A., G. C. B. Guerra, D. F. S. Araujo, R. F. Araujo Junior, T. A. D. G. Machado, A. A. de Araujo, T. A. S. de Lima, H. E. M. Garcia, L. F. L. I. de Andrade, and R. C. R. E. Queiroga. 2016. Intestinal anti-inflammatory activity of goat milk and goat yoghurt in the acetic acid model of rat colitis. Int. Dairy J. 56:4554. https://doi.org/10.1016/j.idairyj.2015.11.002.

del Carmen, S., A. Miyoshi, V. Azevedo, A. de Moreno de LeBlanc, and J. G. LeBlanc. 2015. Evaluation of a Streptococcus thermophilus strain with innate anti-inflammatory properties as a vehicle for IL-10 cDNA delivery in an acute colitis model. Cytokine 73:177183. https://doi.org/10.1016/j.cyto.2015.02.020.

Derwa, Y., D. J. Gracie, P. J. Hamlin, and A. C. Ford. 2017. Systematic review with meta-analysis: The efficacy of probiotics in inflammatory bowel disease. Aliment. Pharmacol. Ther. 46:389-400. https://doi.org/10.1111/apt.14203.

Di Sabatino, A., R. Morera, R. Ciccocioppo, P. Cazzola, S. Gotti, F P. Tinozzi, S. Tinozzi, and G. R. Corazza. 2005. Oral butyrate for mildly to moderately active Crohn's disease. Aliment. Pharmacol. Ther. 22:789-794. https://doi.org/10.1111/j.1365-2036.2005.02639 $\mathrm{x}$.

Elli, M., M. L. Callegari, S. Ferrari, E. Bessi, D. Cattivelli, S. Soldi, L. Morelli, N. Goupil Feuillerat, and J.-M. Antoine. 2006. Survival of yogurt bacteria in the human gut. Appl. Environ. Microbiol. 72:5113-5117. https://doi.org/10.1128/AEM.02950-05. 
Ghouri, Y. A., D. M. Richards, E. F. Rahimi, J. T. Krill, K. A. Jelinek, and A. W. DuPont. 2014. Systematic review of randomized controlled trials of probiotics, prebiotics, and synbiotics in inflammatory bowel disease. Clin. Exp. Gastroenterol. 7:473-487. https:// doi.org/10.2147/CEG.S27530.

Glick, A. B., A. Wodzinski, P. F. Fu, A. D. Levine, and D. N. Wald. 2013. Impairment of regulatory T-cell function in autoimmune thyroid disease. Thyroid 23:871-878. https://doi.org/10.1089/thy 2012.0514.

Glocker, E.-O., D. Kotlarz, C. Klein, N. Shah, and B. Grimbacher. 2011. IL-10 and IL-10 receptor defects in humans. Ann. N. Y. Acad. Sci. 1246:102-107. https://doi.org/10.1111/j.1749-6632 .2011.06339.x.

Gobbato, N., M. Rachid, and G. Perdigon. 2008. Anti-inflammatory effect of yoghurt in an experimental inflammatory bowel disease in mouse. J. Dairy Res. 75:497-504. https://doi.org/10.1017/ S0022029908003579.

Granato, D., G. F. Branco, A. G. Cruz, J. D. F. Faria, and N. P. Shah. 2010. Probiotic dairy products as functional foods. Compr. Rev. Food Sci. Food Saf. 9:455-470. https://doi.org/10.1111/j.1541 $-4337.2010 .00120 . x$

Hamada, H., E. Bassity, A. Flies, T. M. Strutt, M. de Luz GarciaHernandez, K. K. McKinstry, T. Zou, S. L. Swain, and R. W. Dutton. 2013. Multiple redundant effector mechanisms of $\mathrm{CD} 8^{+} \mathrm{T}$ cells protect against influenza infection. J. Immunol. 190:296-306. https://doi.org/10.4049/jimmunol.1200571.

Holmes, K., L. M. Lantz, B. J. Fowlkes, I. Schmid, and J. V. Giorgi. 2001. Preparation of cells and reagents for flow cytometry. Curr. Protoc. Immunol. 44:5.3.1-5.3.24. https://doi.org/10.1002/ 0471142735.im0503s44.

Ito, M., K. Ohishi, Y. Yoshida, T. Okumura, T. Sato, W. Yokoi, and H. Sawada. 2008. Preventive effect of Streptococcus thermophilus YIT 2001 on dextran sulfate sodium-induced colitis in mice. Biosci. Biotechnol. Biochem. 72:2543-2547. https://doi.org/10.1271/ bbb. 80240 .

Johansson, M. E. V., J. K. Gustafsson, J. Holmen-Larsson, K. S. Jabbar, L. J. Xia, H. Xu, F. K. Ghishan, F. A. Carvalho, A. T. Gewirtz, H. Sjovall, and G. C. Hansson. 2014. Bacteria penetrate the normally impenetrable inner colon mucus layer in both murine colitis models and patients with ulcerative colitis. Gut 63:281-291. https://doi.org/10.1136/gutjnl-2012-303207.

Kim, C. H., J. Park, and M. Kim. 2014. Gut microbiota-derived short-chain fatty acids, T cells, and inflammation. Immune Netw. 14:277-288. https://doi.org/10.4110/in.2014.14.6.277.

Kim, J. J., M. S. Shajib, M. M. Manocha, and W. I. Khan. 2012. Investigating intestinal inflammation in DSS-induced model of IBD. J. Vis. Exp. 60:e3678. https://doi.org/10.3791/3678.

Koboziev, I., F. Karlsson, S. Zhang, and M. B. Grisham. 2011. Pharmacological intervention studies using mouse models of the inflammatory bowel diseases: Translating preclinical data into new drug therapies. Inflamm. Bowel Dis. 17:1229-1245. https://doi.org/10 $.1002 /$ ibd.21557.

Lane, E. R., T. L. Zisman, and D. L. Suskid. 2017. The microbiota in inflammatory bowel disease: current and therapeutic insights. J. Inflamm. Res. 10:63-73. https://doi.org/10.2147/JIR.S116088.

Levy, M., C. A. Thaiss, and E. Elinav. 2016. Metabolites: Messengers between the microbiota and the immune system. Genes Dev. 30:1589-1597. https://doi.org/10.1101/gad.284091.116.

Lorea Baroja, M., P. V. Kirjavainen, S. Hekmat, and G. Reid. 2007. Anti-inflammatory effects of probiotic yogurt in inflammatory bowel disease patients. Clin. Exp. Immunol. 149:470-479. https:// doi.org/10.1111/j.1365-2249.2007.03434.x.

Lourens-Hattingh, A., and B. C. Viljoen. 2001. Yogurt as probiotic carrier food. Int. Dairy J. 11:1-17. https://doi.org/10.1016/s0958 $-6946(01) 00036-\mathrm{x}$.

Macpherson, A. J., and N. L. Harris. 2004. Interactions between commensal intestinal bacteria and the immune system. Nat. Rev. Immunol. 4:478-485. https://doi.org/10.1038/nri1373.

Maslowski, K. M., A. T. Vieira, A. Ng, J. Kranich, F. Sierro, D. Yu, H. C. Schilter, M. S. Rolph, F. Mackay, D. Artis, R. J. Xavier, M. M. Teixeira, and C. R. Mackay. 2009. Regulation of inflammatory re- sponses by gut microbiota and chemoattractant receptor GPR43. Nature 461:1282-1286. https://doi.org/10.1038/nature08530.

Morrison, D. J., and T. Preston. 2016. Formation of short chain fatty acids by the gut microbiota and their impact on human metabolism. Gut Microbes 7:189-200. https://doi.org/10.1080/19490976 .2015 .1134082 .

Naito, Y., T. Takagi, O. Handa, T. Ishikawa, S. Nakagawa, T. Yamaguchi, N. Yoshida, M. Minami, M. Kita, J. Imanishi, and T. Yoshikawa. 2003. Enhanced intestinal inflammation induced by dextran sulfate sodium in tumor necrosis factor-alpha deficient mice. J. Gastroenterol. Hepatol. 18:560-569. https://doi.org/10 .1046/j.1440-1746.2003.03034.x.

Ng, W. F., P. J. Duggan, F. Ponchel, G. Matarese, G. Lombardi, A. D. Edwards, J. D. Isaacs, and R. I. Lechler. 2001. Human CD $4^{+} \mathrm{CD} 25^{+}$ cells: A naturally occurring population of regulatory T cells. Blood 98:2736-2744. https://doi.org/10.1182/blood.V98.9.2736.

Noti, M., N. Corazza, C. Mueller, B. Berger, and T. Brunner. 2011 TNF suppresses acute intestinal inflammation by inducing local glucocorticoid synthesis. J. Exp. Med. 207:1057-1066. https://doi .org/10.1084/jem.20090849.

Ogita, T., M. Nakashima, H. Morita, Y. Saito, T. Suzuki, and S. Tanabe. 2011. Streptococcus thermophilus ST28 ameliorates colitis in mice partially by suppression of inflammatory Th17 cells. J. Biomed. Biotechnol. 2011:378417. https://doi.org/10.1155/2011/ 378417.

Putt, K. K., R. Pei, H. M. White, and B. W. Bolling. 2017. Yogurt inhibits intestinal barrier dysfunction in Caco-2 cells by increasing tight junctions. Food Funct. 8:406-414. https://doi.org/10.1039/ c6fo01592a.

Richardson, J. P., J. Ho, and J. R. Naglik. 2018. Candida-Epithelial interactions. J. Fungi 4:22. https://doi.org/10.3390/jof4010022.

Rose, W. A., 2nd, K. Sakamoto, and C. A. Leifer. 2012. Multifunctional role of dextran sulfate sodium for in vivo modeling of intestinal diseases. BMC Immunol. 13:41. https://doi.org/10.1186/ 1471-2172-13-41.

Scardovi, V. 1986. Genus Bifidobacterium. Pages 1418-1434 in Bergey's Manual of Systematic Bacteriology. Vol. 2. P. H. A. Sneath, N. S. Mair, M. E. Sharpe, and J.G. Holt, ed. Williams and Wilkins, Baltimore, MD.

Sengupta, R., E. Altermann, R. C. Anderson, W. C. McNabb, P. J. Moughan, and N. C. Roy. 2013. The role of cell surface architecture of lactobacilli in host-microbe interactions in the gastrointestinal tract. Mediators Inflamm. 2013:237921. https://doi.org/10 $.1155 / 2013 / 237921$.

Sheikhi, A., M. Shakerian, H. Giti, M. Baghaeifar, A. Jafarzadeh, V. Ghaed, M. R. Heibor, N. Baharifar, Z. Dadafarin, and G. Bashirpour. 2016. Probiotic yogurt culture Bifidobacterium animalis ssp. lactis BB-12 and Lactobacillus acidophilus LA-5 modulate the cytokine secretion by peripheral blood mononuclear cells from patients with ulcerative colitis. Drug Res. (Stuttg.) 66:300-305. https://doi.org/10.1055/s-0035-1569414.

Shrikant, P. A., R. Rao, Q. Li, J. Kesterson, C. Eppolito, A. Mischo, and P. Singhal. 2010. Regulating functional cell fates in CD8 T cells. Immunol. Res. 46:12-22. https://doi.org/10.1007/s12026-009 -8130-9.

Smith, P. M., M. R. Howitt, N. Panikov, M. Michaud, C. A. Gallini, M. Bohlooly-Y, J. N. Glickman, and W. S. Garret. 2013. The microbial metabolites, short-chain fatty acids, regulate colonic Treg cell homeostasis. Science 341:569-573. https://doi.org/10.1126/ science. 1241165.

Swidsinski, A., V. Loening-Baucke, S. Bengmark, J. Scholze, and Y. Doerffeld. 2008. Bacterial biofilm suppression with antibiotics for ulcerative and indeterminate colitis: consequences of aggressive treatment. Arch. Med. Res. 39:198-204. https://doi.org/10.1016/ j.arcmed.2007.08.001.

Takamura, T., D. Harama, S. Fukumoto, Y. Nakamura, N. Shimokawa, K. Ishimaru, S. Ikegami, S. Makino, M. Kitamura, and A. Nakao. 2011. Lactobacillus bulgaricus OLL1181 activates the aryl hydrocarbon receptor pathway and inhibits colitis. Immunol. Cell Biol. 89:817-822. https://doi.org/10.1038/icb.2010.165. 
Tanoue, T., K. Atarashi, and K. Honda. 2016. Development and maintenance of intestinal regulatory T cells. Nat. Rev. Immunol. 16:295-309. https://doi.org/10.1038/nri.2016.36.

Topping, D. L., and P. M. Clifton. 2001. Short-chain fatty acids and human colonic function: Roles of resistant starch and nonstarch polysaccharides. Physiol. Rev. 81:1031-1064. https://doi.org/10 .1152 /physrev.2001.81.3.1031.

Ukena, S. N., A. Singh, U. Dringenberg, R. Engelhardt, U. Seidler, W. Hansen, A. Bleich, D. Bruder, A. Franzke, G. Rogler, S. Suerbaum, J. Buer, F. Gunzer, and A. M. Westendorf. 2007. Probiotic Escherichia coli Nissle 1917 inhibits leaky gut by enhancing mucosal integrity. PLoS One 2:e1308. https://doi.org/10.1371/journal pone.0001308.

Vieira, P. L., J. R. Christensen, S. Minaee, E. J. O'Neill, F. J. Barrat, A. Boonstra, T. Barthlott, B. Stockinger, D. C. Wraith, and A. O'Garra. 2004. IL-10-Secreting regulatory T cells do not express Foxp3 but have comparable regulatory function to naturally occurring $\mathrm{CD}^{+} \mathrm{CD}_{25}{ }^{+}$regulatory T cells. J. Immunol. 172:5986-5993. https://doi.org/10.4049/jimmunol.172.10.5986.

Wasilewska, E., L. H. Markiewicz, and M. Bielecka. 2008. Bifidobacterium strains inhabiting the gastrointestinal tract of rat as potential probiotics for animals. J. Anim. Feed Sci. 17:398-410. https:/ /doi.org/10.22358/jafs/66634/2008.
Wasilewska, E., J. Ratowska, M. Bielecka, Z. Zduńczyk, and J. Jankowski. 2010. Mannanoligosaccharides or flavomycin in turkeys diets: effect on mucosa-associated microflora and growth performance. J. Anim. Feed Sci. 19:599-612. https://doi.org/10.22358/ jafs $/ 66327 / 2010$.

Wasilewska, E., and B. Wroblewska. 2018. Effectiveness and safety of probiotic preparations in clinical treatment of inflammatory bowel disease. Postepy Hig. Med. Dosw. 72:159-174. https://doi.org/10 $.5604 / 01.3001 .0011 .6471$.

Wroblewska, B., A. Kaliszewska, P. Kolakowski, K. Pawlikowska, and A. Troszynska. 2011. Impact of transglutaminase reaction on the immunoreactive and sensory quality of yoghurt starter. World J. Microbiol. Biotechnol. 27:215-227.

Zlotkowska, D., E. Wasilewska, E. Kubicka, and B. Wroblewska. 2012. The effect of pea albumins on immune response in mice. Cent. Eur. J. Immunol. 37:232-236. https://doi.org/10.5114/ceji.2012.30799.

Zorn, E., E. A. Nelson, M. Mohseni, F. Porcheray, H. Kim, D. Litsa, R. Bellucci, E. Raderschall, C. Canning, R. J. Soiffer, D. A. Frank, and J. Ritz. 2006. IL-2 regulates FOXP3 expression in human $\mathrm{CD} 4^{+} \mathrm{CD} 25^{+}$regulatory $\mathrm{T}$ cells through a STAT-dependent mechanism and induces the expansion of these cells in vivo. Blood 108:1571-1579. https://doi.org/10.1182/blood-2006-02-004747. 